\title{
Shock-Wave Equations of State for Rocks and Minerals ${ }^{1}$
}

\author{
Don L. Anderson \\ Seismological Laboratory, California Institute of Technology \\ Pasadena, California 91105 \\ Hiroo Kanamori \\ Earthquake Research Institute, University of Tokyo, Tokyo, Japan
}

\begin{abstract}
A method is proposed for estimating the zero-pressure parameters of the high-pressure, high-temperature phases formed by intense shock loading of rocks and minerals. The method involves an empirical relationship between the zero-pressure mean molar volume and the slope at the base of the $P-V$ curve. Equations of state are fitted to shock-wave data for eighteen rocks and minerals. Most of the materials collapsed to a denser phase or assemblage of phases when shocked to sufficiently high pressure. If a phase change occurs, parameters of the high-pressure phase are found for a range of $\rho_{0}$ from both the raw Hugoniot and an estimated metastable Hugoniot. The polymorphic transitions involve a considerable reduction in volume, ranging from 33 to $49 \%$ for feldspar and quartz-rich rocks such as albitite, anorthosite, and granite, $20 \%$ for such basic rocks as diabase and dunite, and about $12 \%$ for some dense already closely packed minerals such as spinel, hematite, and magnetite. The parameter $(d K / d P)_{0}$, which is related to the Grüneisen ratio, is found to decrease across phase changes and upon iron substitution.
\end{abstract}

\section{INTRODUCTION}

Shock-wave data are at present the only sources of information on the compressibility and polymorphism of silicates and oxides at pressures in excess of $300 \mathrm{~kb}$. These data complement the lower pressure ultrasonic and X-ray diffraction data and the relatively low-pressure, high-temperature phase equilibria studies on silicates and analog compounds.

Prior to the availability of shock-wave data, discussions of the composition and crystal structure of the deep mantle relied heavily on the extrapolation of low-pressure data by means of semi-empirical equations of state (mainly the equations of Birch and Murnaghan) and on the study of materials thought to be useful analogs of materials in the earth's mantle. It is now possible to make direct comparisons of seismic data with the density and compressibility of a variety of materials tested with shockwave techniques.

Most silicates that have been shocked to sufficiently high pressure undergo solid-solid

\footnotetext{
${ }^{1}$ Contribution 1515, Division of Geological Sciences, California Institute of Technology, Pasadena.
}

phase changes, which supports conclusions based on the behavior of analog compounds [Birch, 1952; Ringwood, 1966]. The behavior of these high-pressure phases as a function of temperature and pressure and their zero-pressure properties can be extracted from the present shock-wave data only after a variety of assumptions have been made.

As a first step in any reduction scheme it is convenient to fit the raw shock-wave data with a simple equation of state.

\section{Analysis}

We have fitted the raw Hugoniot data with the Birch-Murnaghan equation of state

$$
\begin{aligned}
P_{H}=\left(3 K_{0} / 2\right) & {\left[\left(\rho / \rho_{0}\right)^{7 / 3}-\left(\rho / \rho_{0}\right)^{5 / 3}\right] } \\
\cdot & \left\{1-\xi\left[\left(\rho / \rho_{0}\right)^{2 / 3}-1\right]\right\}
\end{aligned}
$$

where the adjustable parameters are $K_{0}$, the zero-pressure bulk modulus, and $\xi$ which is $3 / 4\left(4-K_{0}^{\prime}\right)$ in which $K_{0}^{\prime}$ is the pressure derivative of $K$ at $P=0$. As initially derived, equation 1 is an isothermal equation of state, but, as Clark [1959] has pointed out, it is also appropriate, with different $K_{0}$ and $\xi$, for adiabatic compression. It is also a useful two- 
parameter equation for fitting raw Hugoniot data. For most isothermal compression experiments $|\xi|<0.5$, with zero being its most frequent value [Birch, 1952].

The raw Hugoniot data have also been fitted to a Murnaghan equation of state

$$
P_{H}=\left(K_{0} / n\right)\left[\left(\rho / \rho_{0}\right)^{n}-1\right]
$$

where $K_{0}$ and $n$ are the adjustable parameters. The parameter $n$ is $K_{0}^{\prime}$, a number close to 4 for many elements and compounds. This form of the Murnaghan equation of state is based on the assumption that the bulk modulus is a linear function of pressure.

A third equation of state that has been used to fit Hugoniot data is the linear $U_{s}-U_{p}$ equation [McQueen et al., 1967a], which leads to

$$
P_{H}=\frac{K_{n}\left[1-\left(\rho_{0} / \rho\right)\right]}{\left[1-\lambda\left\{1-\left(\rho_{0} / \rho\right)\right\}\right]^{2}}
$$

This again is a two-parameter equation of state where $K_{0}$ and $\lambda$ are the parameters to be found from the data.

When the shocked material transforms at high pressure to a new phase, the zero-pressure density, $\rho_{0}$, of this new phase is usually not known. Thus, equations 1,2 , and 3 become three-parameter equations of state where $\rho_{0}$ must also be determined by the shock-wave results. This places severe demands on available shock-wave data, considering the small number of points and the scatter in the highpressure regime. In some cases, the density of the presumed high-pressure phase is known, e.g. stishovite, in the case of shocked quartz. In most other cases, the shock-wave data are the only direct information on the properties of the high-pressure phase.

Our approach will be to fit the Hugoniot data with several values for $\rho_{0}$. In most cases, an equally good fit can be obtained for a fairly wide range of initial densities, indicating that this parameter cannot be determined with any precision directly from the data. In a later section we will invoke an empirical relationship between $K_{0}$ and $\rho_{0}$ to decide which $\rho_{0}$ value is most appropriate.

An analytic expression for the raw Hugoniot data facilitates the reduction of these data to metastable Hugoniots, adiabats, and isotherms. For example, the difference in pressure at a given $\rho / \rho_{0}$ between the raw Hugoniot data, with the low-density phase as starting material, and the metastable Hugoniot, with the high-pressure phase as the starting material, is [McQueen et al., 1963]

$$
\Delta P=\frac{\rho \gamma\left(x P-2 \rho_{b} \Delta E_{0}\right)}{\rho_{b}(2+\gamma)-\rho \gamma}
$$

where $x$ is the relative difference in density between the zero-pressure densities of the highand low-pressure phases $\left(\rho_{b}-\rho_{a}\right) / \rho_{a}, \gamma$ is the Grüneisen ratio of the high-pressure phase, $\Delta E_{0}$ is the difference in formation energy, and $\rho$ is the density at pressure $P$ on the raw Hugoniot. There is a similar offset of the Hugoniot from the corresponding hydrostat due to onedimensional strength effects.

\section{Equation of State Parameters}

Most of the shock-wave data used in the present analysis were supplied in preprint form by Robert G. McQueen and represent work done at Los Alamos by R. G. McQueen, S. P. Marsh, and F. N. Fritz. Some have subsequently been published by McQueen et al. [1967a] and Birch [Clark, 1966]. The reader is referred to these two sources for tabulations of the original data.

All the materials tested except $\mathrm{MgO}, \mathrm{Al}_{2} \mathrm{O}_{3}$, $\mathrm{MnO}_{2}$, and possibly eclogite, underwent phase changes at high pressure. The parameters in Table 1 and 2 refer to the high-pressure phase. A starting density $\rho_{0}$ is assigned, and the BirchMurnaghan parameters $K_{0}$ and $\xi$ are found by a straightforward least-squares fit to the raw Hugoniot data; these values are tabulated in columns 2 and 4 of Table 1. The Grüneisen ratio, at zero pressure, of the high-pressure phase is determined with Slater's assumption $\gamma_{0}=(11-4 \xi) / 6$. The Murnaghan parameters $\Phi_{0}=\left(K_{0} / \rho_{0}\right)$ and $n=(d K / d P)_{0}$, representing a least-squares fit of equation 2 to the data for an assigned $\rho_{0}$, are given in Table 2 . The parameters $\psi_{0}$ and $\psi_{0}^{\prime}$ will be discussed later. The last column in Table 2 gives the pressure range over which the data were obtained. The relative standard deviation of the computed and measured densities is always less than $1 \%$ and is usually less than $0.5 \%$. There is very little difference in the goodness of fit over the adopted range of $\rho_{0}$. For example, the best fit Murnaghan equation to the iron-rich dunite 
TABLE 1. Birch-Murnaghan Parameters for High-Pressure Hugoniot Data

\begin{tabular}{|c|c|c|c|c|c|c|c|c|c|}
\hline Material & $\rho_{0}, \mathrm{~g} / \mathrm{cm}^{3}$ & $K_{0}, \mathrm{Mb}$ & $\begin{array}{c}\Phi_{0} \\
\mathrm{~km}^{2} / \mathrm{sec}^{2}\end{array}$ & $\xi$ & $\gamma_{0}$ & $\partial K / \partial P$ & $\begin{array}{c}\text { Std. } \\
\text { Dev., } \\
\text { Mb }\end{array}$ & $\psi_{0}$ & $\psi_{0}^{\prime}$ \\
\hline \multicolumn{10}{|c|}{ Raw Hugoniot } \\
\hline Albitite & 3.40 & 0.807 & 23.75 & -2.19 & 3.29 & 6.92 & 0.03662 & 0.0580 & 0.0242 \\
\hline Sample density & 3.50 & 1.118 & 31.95 & -1.32 & 2.71 & 5.76 & 0.03631 & 0.0541 & 0.0227 \\
\hline$=2.61 \mathrm{~g} / \mathrm{cm}^{3}$ & 3.60 & 1.522 & 42.29 & -0.55 & 2.20 & 4.73 & 0.03587 & 0.0507 & 0.0214 \\
\hline $\bar{M}=20.4$ grams & 3.70 & 2.055 & 55.54 & 0.19 & 1.71 & 3.75 & 0.03530 & 0.0475 & 0.0202 \\
\hline$\Delta E_{0}=0.007 \times 10^{9}$ & 3.80 & 2.770 & 72.88 & 0.95 & 1.2 & 2.73 & 0.03471 & 0.0446 & 0.0190 \\
\hline \multicolumn{10}{|c|}{ Metastable Hugoniot } \\
\hline & 3.40 & 0.861 & 25.34 & -0.82 & 2.38 & 5.10 & 0.03653 & 0.0568 & 0.0238 \\
\hline & 3.50 & 1.123 & 32.08 & -0.26 & 2.01 & 4.34 & 0.03614 & 0.0540 & 0.0227 \\
\hline & 3.60 & 1.457 & 40.46 & 0.30 & 1.63 & 3.60 & 0.03564 & 0.0514 & 0.0217 \\
\hline & 3.70 & 1.891 & 51.10 & 0.89 & 1.24 & 2.81 & 0.03505 & 0.0489 & 0.0207 \\
\hline & 3.80 & 2.467 & 64.93 & 1.56 & 0.80 & 1.92 & 0.03456 & 0.0464 & 0.0196 \\
\hline \multicolumn{10}{|c|}{ Raw Hugoniot } \\
\hline Anorthosite & 3.40 . & 0.948 & 27.88 & -0.81 & 2.37 & 5.08 & 0.04142 & 0.0534 & 0.0225 \\
\hline Sample density & 3.50 & 1.252 & 35.76 & -0.27 & 2.01 & 4.36 & 0.04154 & 0.0506 & 0.0214 \\
\hline$=2.74 \mathrm{~g} / \mathrm{cm}^{3}$ & 3.60 & 1.643 & 45.64 & 0.27 & 1.65 & 3.64 & 0.04200 & 0.0480 & 0.0203 \\
\hline $\bar{M}=21.0$ grams & 3.70 & 2.155 & 58.23 & 0.83 & 1.28 & 2.90 & 0.04333 & 0.0455 & 0.0193 \\
\hline \multicolumn{10}{|c|}{ Metastable Hugoniot } \\
\hline & 3.40 & 0.994 & 29.23 & -0.01 & 1.84 & 4.01 & 0.04153 & 0.0526 & 0.0222 \\
\hline & 3.50 & 1.257 & 35.93 & 0.41 & 1.56 & 3.45 & 0.04176 & 0.0505 & 0.0213 \\
\hline & 3.60 & 1.591 & 44.20 & 0.86 & 1.26 & 2.86 & 0.04249 & 85 & 0.0205 \\
\hline & 3.70 & 2.020 & 54.61 & 1.34 & 0.94 & 2.21 & 0.04439 & 0.0464 & 0.0197 \\
\hline \multicolumn{10}{|c|}{ Raw Hugoniot } \\
\hline Bronzitite (Stillwater) & 3.30 & 0.876 & 26.5 & -0.09 & 1.89 & 4 & & & 0.0227 \\
\hline Sample density & 3.40 & 1.073 & 31.57 & 0.14 & 1.74 & 3.82 & 0.02353 & 0.0520 & 0.0220 \\
\hline$=3.28 \mathrm{~g} / \mathrm{cm}^{3}$ & 3.50 & 1.313 & 37.51 & 0.37 & 1.59 & 3.51 & 0.02330 & 0.0505 & 0.0214 \\
\hline $\bar{M}=20.7$ grams & 3.60 & 1.604 & 44.55 & 0.61 & 1.42 & 3.18 & 0.02306 & 0.0491 & 0.0208 \\
\hline$\Delta E_{0}=0.0016 \times 10^{9}$ & 3.70 & 1.960 & 52.97 & 0.88 & 1.24 & 2.82 & 0.02286 & 0.0476 & 0.0201 \\
\hline $\mathrm{ergs} / \mathrm{g}$ & 3.80 & 2.399 & 63.14 & 1.19 & 1.04 & 2.42 & 0.02282 & 0.0461 & 0.0195 \\
\hline \multicolumn{10}{|c|}{ Metastable Hugoniot } \\
\hline & 3.30 & 0.896 & 27.15 & -0.04 & 1.86 & 4 & 0. & 0.0530 & 0.0225 \\
\hline & 3.40 & & 31.87 & 0.24 & 1.68 & & 0. & 0.0518 & 0.0220 \\
\hline & 3.50 & 1.303 & 37.22 & 0.50 & 1.50 & 3.34 & 0.02328 & 0.0506 & 0.0214 \\
\hline & 3.60 & 1.563 & 43.41 & 0.76 & 1.33 & 2.99 & 0.02304 & 0.0495 & 0.0209 \\
\hline & 3.70 & 1.874 & 50.66 & 1.04 & 1.14 & 2.61 & 0.02284 & 0.0483 & 0.0204 \\
\hline & 3.80 & 2.254 & 59.30 & 1.34 & 0.94 & 2.21 & 0.02283 & 0.0471 & 0.0199 \\
\hline \multicolumn{10}{|c|}{ Raw Hugoniot } \\
\hline Corundum (ceran & 0.00 & 1. VeUT & & & 2.7 & 5 . & 0.01634 & 0.0532 & 0.0221 \\
\hline Sample density & 3.85 & 1.914 & 49.71 & -0.91 & 2.44 & 5.21 & 0.01731 & 0.0513 & 0.0214 \\
\hline$=3.83 \mathrm{~g} / \mathrm{cm}^{3}$ & 3.90 & 2.235 & 57.31 & -0.48 & 2.16 & 4.64 & 0.01916 & 0.0496 & 0.0207 \\
\hline $\bar{M}=20.4$ grams & 3.95 & 2.605 & 65.96 & -0.07 & 1.88 & 4.09 & 0.02224 & 0.0479 & 0.0201 \\
\hline
\end{tabular}

Raw Hugoniot

Diabase (Centreville) Sample density $=2.98 \mathrm{~g} / \mathrm{cm}^{3}$ $\bar{M}=21.8$ grams $\Delta E_{0}=0.004 \times 10^{9}$ ergs/g

$\begin{array}{ll}3.40 & 0.841 \\ 3.50 & 1.080 \\ 3.60 & 1.379 \\ 3.70 & 1.760 \\ 3.80 & 2.250\end{array}$

\subsection{5}

30.85

38.32

47.57

59.20

$\begin{array}{rrr}-0.61 & 2.24 & 4.81 \\ -0.20 & 1.97 & 4.27 \\ 0.20 & 1.70 & 3.73 \\ 0.62 & 1.42 & 3.18 \\ 1.07 & 1.12 & 2.57\end{array}$

0.03073

0.03064

0.03084

0.03178

0.03437
0.0535

0.0512

0.0490

0.0468

0.0447
0.0224

0.0215

0.0206

0.0197

0.0197 
TABLE 1. (continued)

\begin{tabular}{|c|c|c|c|c|c|c|c|c|c|}
\hline Material & $\rho_{0}, \mathrm{~g} / \mathrm{cm}^{3}$ & $K_{0 .}, \mathrm{Mb}$ & $\begin{array}{c}\Phi_{0} \\
\mathrm{~km}^{2} / \mathrm{sec}^{2}\end{array}$ & $\xi$ & $\gamma_{0}$ & $\partial K / \partial P$ & $\begin{array}{c}\text { Std. } \\
\text { Dev., } \\
\text { Mb }\end{array}$ & $\psi_{0}$ & $\psi_{0}^{\prime}$ \\
\hline \multicolumn{10}{|c|}{ Metastable Hugoniot } \\
\hline & 3.40 & 0.870 & 25.58 & -0.12 & 1.92 & 4.16 & 0.03079 & 0.0529 & 0.0222 \\
\hline & 3.50 & 1.082 & 30.91 & 0.24 & 1.68 & 3.69 & 0.03073 & 0.0512 & 0.0215 \\
\hline & 3.60 & 1.343 & 37.30 & 0.60 & 1.44 & 3.20 & 0.03106 & 0.0494 & 0.0208 \\
\hline & 3.70 & 1.668 & 45.09 & 0.98 & 1.18 & 2.70 & 0.03231 & 0.0477 & 0.0200 \\
\hline & 3.80 & 2.081 & 54.77 & 1.40 & 0.90 & 2.14 & 0.03555 & 0.0459 & 0.0193 \\
\hline \multicolumn{10}{|c|}{ Raw Hugoniot } \\
\hline Diabase (Frederick) & 3.30 & 0.693 & 21.00 & -0.78 & 2.36 & 5.05 & 0.02492 & 0.0556 & 0.0233 \\
\hline Sample density & 3.40 & 0.891 & 26.19 & -0.39 & 2.09 & 4.52 & 0.02640 & 0.0533 & 0.0224 \\
\hline$=3.01 \mathrm{~g} / \mathrm{cm}^{3}$ & 3.50 & 1.138 & 32.52 & -0.00 & 1.84 & 4.00 & 0.02863 & 0.0510 & 0.0215 \\
\hline $\bar{M}=21.5$ grams & 3.60 & 1.450 & 40.28 & 0.39 & 1.57 & 3.48 & 0.03201 & 0.0489 & 0.0206 \\
\hline$\Delta E_{0}=0.005 \times 10^{9}$ & 3.70 & 1.847 & 49.93 & 0.81 & 1.30 & 2.92 & 0.03722 & 0.0467 & 0.0197 \\
\hline \multicolumn{10}{|c|}{ Metastable Hugoniot } \\
\hline & 3.30 & 0.753 & 22.81 & -0.28 & 2.02 & 4.38 & 0.02552 & 0.0541 & 0.0228 \\
\hline & 3.40 & 0.937 & 27.56 & 0.07 & 1.79 & 3.90 & 0.02724 & 0.0524 & 0.0220 \\
\hline & 3.50 & 1.161 & 33.19 & 0.42 & 1.55 & 3.44 & 0.02984 & 0.0507 & 0.0213 \\
\hline & 3.60 & 1.438 & 39.95 & 0.78 & 1.32 & 2.96 & 0.03378 & 0.0490 & 0.0206 \\
\hline & 3.70 & 1.784 & 48.23 & 1.16 & 1.06 & 2.45 & 0.03977 & 0.0473 & 0.0199 \\
\hline \multicolumn{10}{|c|}{ Raw Hugoniot } \\
\hline Dunite & 3.75 & 1.358 & 36.21 & -1.24 & 2.66 & 5.65 & 0.03148 & 0.0535 & 0.0222 \\
\hline (Twin Sisters Mt.) & 3.85 & 1.770 & 45.96 & -0.65 & 2.27 & 4.87 & 0.03157 & 0.0507 & 0.0211 \\
\hline Sample density & 3.95 & 2.289 & 57.95 & -0.09 & 1.89 & 4.11 & 0.03171 & 0.0482 & 0.0201 \\
\hline$=3.32 \mathrm{~g} / \mathrm{cm}^{3}$ & 4.05 & 2.950 & 72.84 & 0.49 & 1.51 & 3.35 & 0.03194 & 0.0457 & 0.0191 \\
\hline \multicolumn{10}{|c|}{ Metastable Hugoniot } \\
\hline & 3.75 & 1.447 & 38.58 & -0.59 & 2.23 & 4.78 & 0.03151 & 0.0524 & 0.0218 \\
\hline & 3.85 & 1.824 & 47.39 & -0.09 & 1.89 & 4.12 & 0.03162 & 0.0502 & 0.0209 \\
\hline & 3.95 & 2.291 & .58 .00 & 0.40 & 1.57 & 3.46 & 0.03179 & 0.0481 & 0.0201 \\
\hline & 4.05 & 2.875 & 71.00 & 0.92 & 1.22 & 2.78 & 0.03206 & 0.0461 & 0.0193 \\
\hline \multicolumn{10}{|c|}{ Raw Hugoniot } \\
\hline Dunite (iron rich) & 4.40 & 1.746 & 39.69 & -0.31 & 2.04 & 4.42 & 0.04736 & 0.0514 & 0.0204 \\
\hline Sample density & 4.50 & 2.154 & 47.88 & 0.10 & 1.77 & 3.87 & 0.04727 & 0.0494 & 0.0197 \\
\hline$=3.80 \mathrm{~g} / \mathrm{cm}^{3}$ & 4.60 & 2.653 & 57.67 & 0.51 & 1.49 & 3.32 & 0.04720 & 0.0474 & 0.0189 \\
\hline $\begin{array}{l}\bar{M}=25.1 \text { grams } \\
\Delta E_{0}=0.003 \times 10^{9}\end{array}$ & 4.70 & 3.268 & 69.53 & 0.96 & 1.20 & 2.73 & 0.04717 & 0.0455 & 0.0182 \\
\hline \multicolumn{10}{|c|}{ Metastable Hugoniot } \\
\hline & 4.40 & 1.714 & 38.95 & 0.07 & 1.79 & 3.91 & 0.04734 & 0.0517 & 0.0205 \\
\hline & 4.50 & 2.070 & 46.01 & 0.44 & 1.54 & 3.41 & 0.04725 & 0.0500 & 0.0199 \\
\hline & 4.60 & 2.500 & 54.36 & 0.83 & 1.28 & 2.89 & 0.04718 & 0.0484 & 0.0193 \\
\hline & 4,70 & $3: 025$ & 64.35 & 1.25 & 1.00 & 2.33 & 0.04719 & 0.0467 & 0.0186 \\
\hline \multicolumn{10}{|c|}{ Raw Hugoniot } \\
\hline Eclogite & 3.40 & 1.057 & 31.09 & 0.21 & 1.69 & 3.72 & 0.02947 & 0.0485 & 0.0205 \\
\hline Sample density & 3.45 & 1.174 & 34.02 & 0.34 & 1.61 & 3.55 & 0.02957 & 0.0478 & 0.0202 \\
\hline$=3.56 \mathrm{~g} / \mathrm{cm}^{3}$ & 3.50 & 1.302 & 37.21 & 0.47 & 1.52 & 3.38 & 0.02976 & 0.0470 & 0.0199 \\
\hline $\bar{M}=22.3$ grams & 3.55 & 1.445 & 40.71 & 0.60 & 1.43 & 3.20 & 0.03007 & 0.0463 & 0.0196 \\
\hline$\Delta E_{0}=0.0 \times 10^{9}$ & 3.60 & 1.604 & 44.55 & 0.74 & $1.34=$ & 3.02 & 0.03005 & 0.0455 & 0.0193 \\
\hline ergs/g & 3.65 & 1.780 & 48.78 & 0.88 & 1.24 & 2.82 & 0.03126 & 0.0448 & 0.0190 \\
\hline
\end{tabular}


TABLE 1. (continued)

Std.

Dev.,

Material $\quad \rho_{0}, \mathrm{~g} / \mathrm{cm}^{3} \quad K_{0}, \mathrm{Mb} \quad \begin{gathered}\mathrm{km}^{2} / \mathrm{sec}^{2} \\ \xi\end{gathered} \gamma_{0} \quad \partial K / \partial P \quad \mathrm{Mb}$ $\psi_{0} \quad \psi_{0}^{\prime}$

Fayalite
Sample density
$=4.28 \mathrm{~g} / \mathrm{cm}^{3}$
$\bar{M}=29.11 \mathrm{grams}$
$\Delta E_{0}=0.006 \times 10^{9}$
ergs $/ \mathrm{g}$

Forsterite (ceramic)

Sample density

$=3.05 \mathrm{~g} / \mathrm{cm}^{3}$

$\bar{M}=20.10$ grams

$\Delta E_{0}=0.008 \times 10^{9}$

ergs/g
Granite

Sample density

$=2.63 \mathrm{~g} / \mathrm{cm}^{3}$

$\bar{M}=20.60$ grams

$\Delta E_{0}=0.006 \times 10^{9}$

$\mathrm{ergs} / \mathrm{g}$

\section{Hematite \\ Sample density \\ $=5.00 \mathrm{~g} / \mathrm{cm}$ \\ $\bar{M}=31.94$ grams \\ $\Delta E_{0}=0.006 \times 10^{9}$ \\ $\mathrm{ergs} / \mathrm{g}$}

$\begin{array}{lllllllll}4.80 & 1.537 & 32.03 & 0.20 & 1.70 & 3.73 & 0.04473 & 0.0519 & 0.0199 \\ 4.90 & 1.812 & 36.98 & 0.45 & 1.54 & 3.40 & 0.04434 & 0.0505 & 0.0194 \\ 5.00 & 2.136 & 42.71 & 0.71 & 1.36 & 3.06 & 0.04386 & 0.0491 & 0.0189 \\ 5.10 & 2.519 & 49.40 & 0.98 & 1.18 & 2.69 & 0.04331 & 0.0478 & 0.0184 \\ 5.20 & 2.978 & 57.26 & 1.28 & 0.98 & 2.29 & 0.04268 & 0.0464 & 0.0178\end{array}$

Metastable Hugoniot

$\begin{array}{lllllllll}4.80 & 1.610 & 33.55 & 0.55 & 1.47 & 3.27 & 0.04444 & 0.0511 & 0.0197 \\ 4.90 & 1.862 & 37.98 & 0.78 & 1.31 & 2.96 & 0.04401 & 0.0501 & 0.0193 \\ 5.00 & 2.152 & 43.05 & 1.02 & 1.15 & 2.64 & 0.04351 & 0.0490 & 0.0188 \\ 5.10 & 2.494 & 48.90 & 1.29 & 0.98 & 2.28 & 0.04294 & 0.0479 & 0.0184 \\ 5.20 & 2.898 & 55.73 & 1.58 & 0.78 & 1.90 & 0.04233 & 0.0468 & 0.0180\end{array}$

Raw Hugoniot

$\begin{array}{ll}3.90 & 1.585 \\ 4.00 & 2.125 \\ 4.10 & 2.824 \\ 4.20 & 3.745\end{array}$

$\begin{array}{lll}40.64 & -1.52 & 2.85\end{array}$

6.03

0.03177

0.0564

$\begin{array}{lll}53.11 & -0.71 \quad 2.31\end{array}$

4.95

0.03179

0.0529

$\begin{array}{lll}0.06 & 1.79 & 3.92\end{array}$

0.03182

$0.85 \quad 1.27$

2.86

0.03188

0.0497

89.16

0.0468

0.0232

0.0219

0.0206

0.0195

\section{Metastable Hugoniot}

$\begin{array}{lllrlllll}3.90 & 1.619 & 41.51 & -0.51 & 2.17 & 4.68 & 0.03177 & 0.0560 & 0.0231 \\ 4.00 & 2.081 & 52.04 & 0.11 & 1.76 & 3.86 & 0.03179 & 0.0534 & 0.0220 \\ 4.10 & 2.672 & 65.17 & 0.74 & 1.34 & 3.01 & 0.03183 & 0.0507 & 0.0210 \\ 4.20 & 3.441 & 81.93 & 1.44 & 0.87 & 2.08 & 0.03193 & 0.0480 & 0.0200\end{array}$

\section{Raw Hugoniot}

3.70

3.80

3.90

4.00

1.381

1.915

2.634

3.630

37.34

50.39

$\begin{array}{rr}-1.42 & 2.78 \\ -0.46 & 2.14 \\ 0.46 & 1.53 \\ 1.43 & 0.88\end{array}$

5.89

4.62

67.55

90.75

3.39

2.10 $\begin{array}{lll}0.03819 & 0.0537 & 0.0224\end{array}$

$\begin{array}{lll}0.03705 & 0.0499 & 0.0209\end{array}$

$\begin{array}{lll}0.03540 & 0.0465 & 0.0196\end{array}$

$\begin{array}{llll}0.03335 & 0.0432 & 0.0183\end{array}$
Metastable Hugoniot

$\begin{array}{ll}3.70 & 1.318 \\ 3.80 & 1.746 \\ 3.90 & 2.318 \\ 4.00 & 3.105\end{array}$

5.50

5.60

5.70

5.80

5.90

5.50

5.60

5.70

5.80

5.90
2.122

2.443

2.812

3.241

3.740
35.63

45.96

59.45

77.61

Raw Hugoniot

\section{Metastable Hugoniot}

2.209
2.503
2.839
3.223
3.667

$\begin{array}{rr}-0.32 & 2.05 \\ 0.40 & 1.57 \\ 1.16 & 1.06 \\ 2.04 & 0.48\end{array}$

4.43

3.47

2.45

1.29

$\begin{array}{llll}38.58 & 0.38 & 1.58 & 3.50 \\ 43.62 & 0.59 & 1.44 & 3.22 \\ 49.34 & 0.81 & 1.30 & 2.93 \\ 55.88 & 1.04 & 1.14 & 2.61 \\ 63.39 & 1.30 & 0.97 & 2.27\end{array}$

$\begin{array}{lll}0.03790 & 0.0546 & 0.0227 \\ 0.03655 & 0.0515 & 0.0215 \\ 0.03474 & 0.0485 & 0.0203 \\ 0.03276 & 0.0455 & 0.0192\end{array}$

0.03235

0.03264

0.0510

0.0498

0.0487

0.03301

0.03348

0.0475

0.0463

0.0190

0.0185

0.0181

0.03411

0.0177

0.0173

$\begin{array}{lllllll}40.16 & 0.65 & 1.40 & 3.13 & 0.03256 & 0.0503 & 0.0188 \\ 44.70 & 0.86 & 1.26 & 2.86 & 0.03289 & 0.0494 & 0.0184 \\ 49.80 & 1.07 & 1.12 & 2.57 & 0.03331 & 0.0485 & 0.0181 \\ 55.57 & 1.30 & 0.97 & 2.27 & 0.03386 & 0.0476 & 0.0177 \\ 62.16 & 1.55 & 0.80 & 1.94 & 0.03459 & 0.0466 & 0.0174\end{array}$


TABLE 1. (continued)

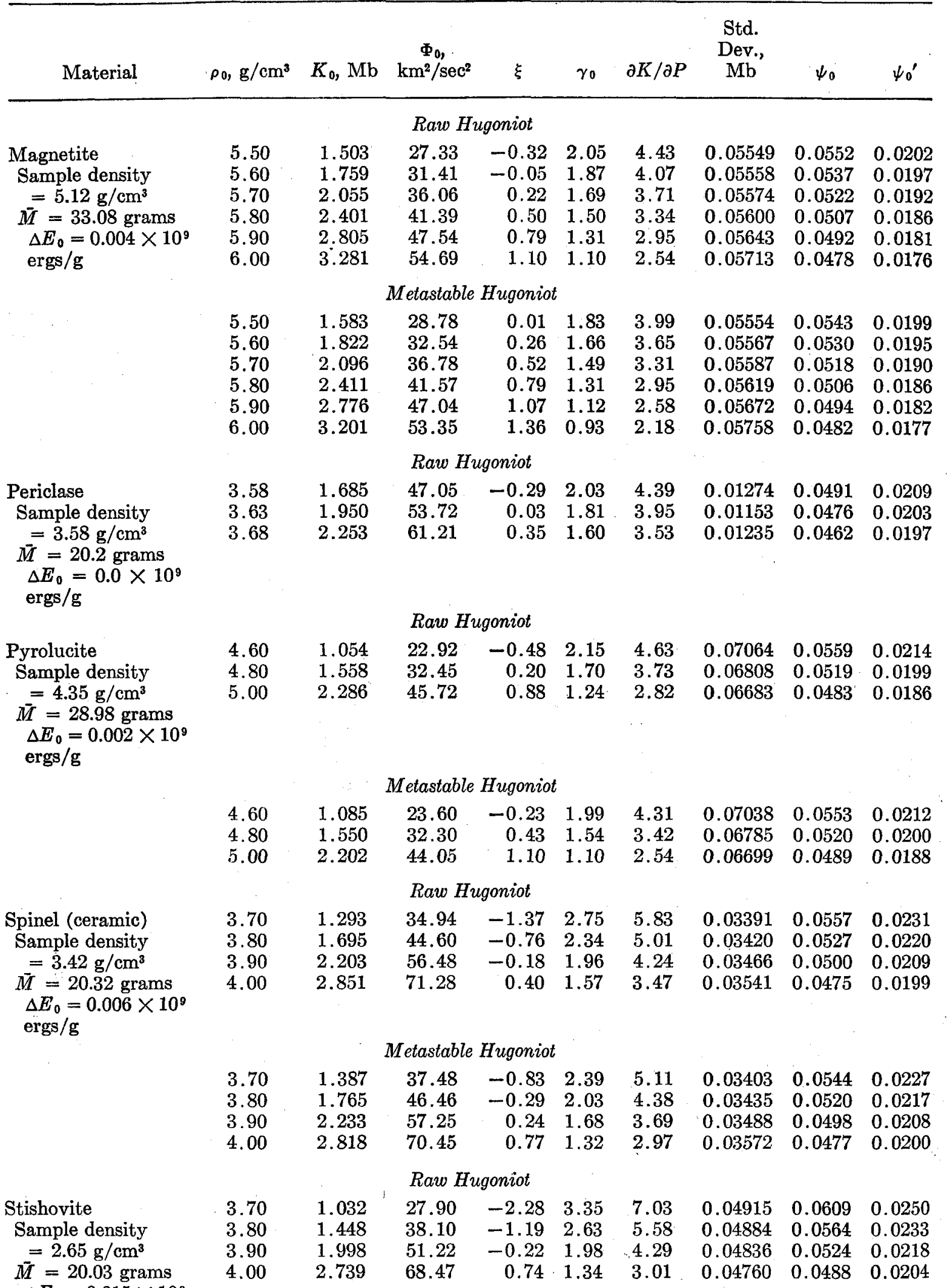


TABLE 1. (continued)

\begin{tabular}{|c|c|c|c|c|c|c|c|c|c|}
\hline Material & $\rho_{0}, \mathrm{~g} / \mathrm{cm}^{3}$ & $K_{0}, \mathrm{Mb}$ & $\begin{array}{c}\boldsymbol{\Phi}_{0} \\
\mathrm{~km}^{2} / \mathrm{sec}^{2}\end{array}$ & $\xi$ & $\gamma_{0}$ & $\partial K / \partial P$ & $\begin{array}{c}\text { Std. } \\
\text { Dev., } \\
\text { Mb }\end{array}$ & $\psi_{0}$ & $\psi_{0}^{\prime}$ \\
\hline \multicolumn{10}{|c|}{ Metastable Hugoniot } \\
\hline & 3.70 & 1.222 & 33.04 & -0.27 & 2.01 & 4.36 & 0.04877 & 0.0576 & 0.0239 \\
\hline & 3.80 & 1.587 & 41.77 & 0.35 & 1.60 & 3.53 & 0.04833 & 0.0547 & 0.0227 \\
\hline & 3.90 & 2.063 & 52.89 & 1.02 & 1.15 & 2.64 & 0.0477 & 0.0519 & 0.0216 \\
\hline & 4.00 & 2.696 & 67.41 & 1.78 & 0.65 & 1.63 & 0.04674 & 0.0491 & 0.0205 \\
\hline
\end{tabular}

Hugoniot data with a zero-pressure density of $4.5 \mathrm{~g} / \mathrm{cm}^{3}$ gives a relative standard deviation in density of $0.785 \%$. For an initial density for the high-pressure phase of $4.7 \mathrm{~g} / \mathrm{cm}^{3}$, the best fit Murnaghan equation has a relative standard deviation of $0.782 \%$. Comparable results are found for all the materials tested. As far as providing an adequate fit to the experimental data, any of the combinations of $\rho_{0}$, $K_{0}$, and $\xi$ or $n$ can be considered equally satisfactory. However, quite different results would be obtained upon extrapolation of differentiation. Note that $\xi$ increases and $n$ decreases as the trial $\rho_{0}$ is increased.

Table 3 gives an example for two starting densities of the computed versus the measured. parameters as a function of pressure for the Twin-Sisters dunite. The measured compression $\left(V / V_{0}\right)$, density $\rho$, and pressure $P$ are given in the first three columns. The pressure $P_{0}$ at corresponding compressions determined from the best fit Birch-Murnaghan equation with $\rho_{0}=3.90 \mathrm{~g} / \mathrm{cm}^{3}$ is given in the fourth column. The standard deviation in pressure is $28.5 \mathrm{~kb}$ or $3.10 \%$. The slope of the fitted Hugoniot $(d P / d \rho)=\Phi$ is given in column five. The parameters of the best fit Birch-Murnaghan equation with $\rho_{0}=3.90 \mathrm{~g} / \mathrm{cm}^{3}$ are $\xi=+0.37$ and $\Phi_{0}=51.6(\mathrm{~km} / \mathrm{sec})^{2}$. The corresponding parameters with $\rho_{0}=4.00 \mathrm{~g} / \mathrm{cm}^{3}$ are $\xi=+0.20$ and $\Phi_{0}=65.0(\mathrm{~km} / \mathrm{sec})^{2}$. The computed pressures for this case are within 1 or $2 \mathrm{~kb}$ of the values computed previously, and the standard deviation is $28.7 \mathrm{~kb}$ or $3.12 \%$. The slope of the Hugoniot, as a function of pressure, is very similar for these two cases. The density and $\Phi$ as a function of pressure computed from the best fit Murnaghan equation for these two densities are given in the last four columns. Again, the fits are equally satisfactory for both starting densities. Note that the $\Phi$ are 4 to $10 \%$ higher than the values given by the BirchMurnaghan equation, which indicates that some care must be taken when comparing seismic velocities with shock-wave results. McQueen et al. [1967a] give an equation for determining the adiabatic bulk sound velocity from the slope of the Hugoniot.

\section{Estimation of Metastable Hugoniot}

McQueen et al. [1963] presented a method for correcting observed Hugoniot data of a high-pressure phase to the Hugoniot that would result if the high-density phase were the (metastable) starting material. As formulated by McQueen et al., the correction involves the Grüneisen ratio $\gamma$ at high pressure, the transition pressure $P_{t}$, and the difference of formation energy of the high-pressure and low-pressure polymorphs $\Delta E_{0}$ (see equation 4). McQueen et al. [1967a] applied this technique in an elaborate study of twelve rocks of geophysical interest. In previous sections, we have fitted Birch-Murnaghan and Murnaghan equations of state to raw Hugoniot data, uncorrected for the effects of strength, phase changes, and temperature.

In this section we estimate the offset of the metastable from the raw Hugoniot curve and fit the Birch-Murnaghan equation of state to these corrected data.

The difference of the formation energy $\Delta E_{0}$ has been estimated from the transition pressures and density changes at the transition read from the raw data; $\gamma$ of the high-pressure phase was arbitrarily taken as unity. The change in entropy at the transition has been ignored. The results are not very sensitive, however, to $\Delta E_{0}$. A complete discussion of more accurate reduction techniques are given by McQueen 
TABLE 2. Murnaghan Parameters for High-Pressure Raw Hugoniot Data

Unless otherwise noted the data are from McQueen et al. [1967a, b], R. G. McQueen (personal communication), and Clark [1966].

\begin{tabular}{|c|c|c|c|c|c|}
\hline Material & $\begin{array}{c}\rho_{0} \\
\mathrm{~g} / \mathrm{cm}^{3}\end{array}$ & $\begin{array}{c}\Phi_{0} \\
\mathrm{~km}^{2} / \mathrm{sec}^{2}\end{array}$ & $\begin{array}{c}n= \\
(d K / d P)_{0}\end{array}$ & $\begin{array}{c}\psi_{0}= \\
\left(\rho_{0} / \bar{M}\right) \Phi_{0}^{-1 / 3}\end{array}$ & $P, \mathrm{Mb}$ \\
\hline \multirow[t]{2}{*}{ Dunite (Twin Sisters) } & 3.65 & 29.1 & 5.37 & 0.0560 & \multirow[t]{4}{*}{$0.73-1.12$} \\
\hline & 3.90 & 49.5 & 4.42 & 0.0501 & \\
\hline & 4.00 & 62.0 & 3.83 & 0.0477 & \\
\hline & $4.04^{5}$ & 68.8 & 3.51 & 0.0466 & \\
\hline \multirow[t]{4}{*}{ Dunite (iron rich) } & 4.50 & 44.6 & 4.04 & 0.0506 & \multirow[t]{4}{*}{$0.65-1.19$} \\
\hline & 4.60 & 54.0 & 3.50 & 0.0485 & \\
\hline & $4.63^{6}$ & 58.0 & 3.28 & 0.0477 & \\
\hline & 4.70 & 66.0 & 2.82 & 0.0463 & \\
\hline \multirow[t]{2}{*}{ Diabase (Centreville) } & 3.40 & 25.7 & 4.12 & 0.0528 & \multirow[t]{2}{*}{$0.36-1.02$} \\
\hline & 3.50 & 31.6 & 3.75 & 0.0508 & \\
\hline \multirow{2}{*}{ Diabase (Frederick) } & 3.40 & 28.5 & 3.70 & 0.0518 & \multirow{2}{*}{$0.33-1.03$} \\
\hline & 3.50 & 34.8 & 3.30 & 0.0499 & \\
\hline \multirow{5}{*}{ Forsterite (Ceramic) } & 3.33 & 11.3 & 6.80 & 0.0738 & \multirow[t]{5}{*}{$0.66-1.04$} \\
\hline & $3.85^{4}$ & 36.6 & 5.55 & 0.0578 & \\
\hline & 3.90 & 40.7 & 5.34 & 0.0564 & \\
\hline & 4.00 & 51.8 & 4.77 & 0.0534 & \\
\hline & 4.10 & 66.5 & 4.00 & 0.0503 & \\
\hline \multirow[t]{3}{*}{ Fayalite } & 4.73 & 28.3 & 3.70 & 0.0533 & \multirow[t]{3}{*}{$0.58-1.14$} \\
\hline & 4.80 & 31.4 & 3.49 & 0.0522 & \\
\hline & 5.00 & 42.4 & 2.75 & 0.0493 & \\
\hline \multirow[t]{4}{*}{ Spinel } & 3.60 & 29.3 & 5.26 & 0.0575 & \multirow[t]{4}{*}{$0.68-1.16$} \\
\hline & 3.80 & 44.7 & 4.55 & 0.0527 & \\
\hline & $3.86^{4}$ & 51.4 & 4.23 & 0.0511 & \\
\hline & 3.90 & 55.6 & 4.05 & 0.0503 & \\
\hline \multirow{6}{*}{ Magnetite } & 5.40 & 23.7 & 4.30 & 0.0568 & \multirow{6}{*}{$0.62-1.31$} \\
\hline & $5.44^{4}$ & 25.1 & 4.22 & 0.0562 & \\
\hline & 5.50 & 27.0 & 4.09 & 0.0554 & \\
\hline & 5.70 & 35.2 & 3.53 & 0.0526 & \\
\hline & 5.90 & 46.6 & 2.75 & 0.0496 & \\
\hline & 6.10 & 62.7 & 1.64 & 0.0464 & \\
\hline \multirow{3}{*}{ Hematite } & 5.50 & 39.3 & 3.07 & 0.0506 & \multirow[t]{3}{*}{$0.90-1.42$} \\
\hline & 5.70 & 50.3 & 2.44 & 0.0483 & \\
\hline & 6.00 & & & & \\
\hline \multirow[t]{3}{*}{ Rutile } & $4.37^{4}$ & 5.68 & 9.20 & 0.0921 & \multirow[t]{3}{*}{$1.03-1.24$} \\
\hline & 5.30 & 39.0 & 7.62 & 0.0484 & \\
\hline & 5.80 & 129.2 & 2.87 & 0.0431 & \\
\hline \multirow{6}{*}{ Periclase } & 3.62 & 49.2 & 3.65 & 0.0489 & $0.3-2.6^{a}$ \\
\hline & 3.45 & 50.6 & 2.92 & 0.0462 & $b$ \\
\hline & 3.62 & 51.8 & 3.06 & 0.0481 & $c$ \\
\hline & $3.57^{7}$ & 51.1 & 3.27 & 0.0477 & $0-0.3^{d}$ \\
\hline & $3.57^{7}$ & 48.4 & 3.92 & 0.0486 & $0.2-1.26$ \\
\hline & 3.57 & 51.5 & 3.09 & 0.0475 & e \\
\hline Pyrolucite & 4.34 & 15.4 & 4.57 & 0.0602 & $0.18-1.20$ \\
\hline & 4.36 & 14.2 & 5.05 & 0.0621 & \\
\hline Stishovite & 4.35 & 106.7 & 2.29 & 0.0458 & $0.6-2.0^{a}$ \\
\hline & 4.35 & 110.0 & 1.91 & 0.0453 & $d$ \\
\hline & 4.28 & 107.9 & 1.97 & 0.0449 & $b$ \\
\hline
\end{tabular}

a Al'tshuler et al. [1965], Hugoniot.

${ }^{\circ}$ Al'tshuler et al. [1965], $4000^{\circ} \mathrm{K}$ isotherm.

c Al'tshuler et al. [1965], $0^{\circ} \mathrm{K}$ isotherm.

a Perez-Albuerne and Drickamer [1965], isothermal compression.

- Isotherm, this paper. 
TABLE 3. Example of Birch-Murnaghan and Murnaghan Fits to High-Pressure Phase of Twin Sister's Dunite

$\rho_{0}=3.90, \xi=-0.37, n=4.42 ;$ and $\rho_{0}=4.0, \xi=+0.20, n=3.83$

\begin{tabular}{|c|c|c|c|c|c|c|c|c|c|c|}
\hline \multirow[b]{3}{*}{$V / V_{0}$} & \multirow[b]{3}{*}{$\begin{array}{c}\rho, \\
\mathrm{g} / \mathrm{cm}^{3}\end{array}$} & \multirow[b]{3}{*}{$\begin{array}{l}P, \\
\mathrm{~kb}\end{array}$} & \multicolumn{4}{|c|}{ Birch-Murnaghan } & \multicolumn{4}{|c|}{ Murnaghan } \\
\hline & & & \multicolumn{2}{|c|}{$\rho_{0}=3.90$} & \multicolumn{2}{|c|}{$\rho_{0}=4.0$} & \multicolumn{2}{|c|}{$\boldsymbol{\rho}_{0}=3.90$} & \multicolumn{2}{|c|}{$\rho_{0}=4.00$} \\
\hline & & & $\begin{array}{l}P_{c} \\
\mathrm{~kb}\end{array}$ & $\begin{array}{c}\Phi, \\
(\mathrm{km} / \mathrm{sec})^{2}\end{array}$ & $\begin{array}{l}P_{c} \\
\mathrm{~kb}\end{array}$ & $\begin{array}{c}\phi \\
(\mathrm{km} / \mathrm{sec})^{2}\end{array}$ & $\begin{array}{l}\rho_{c}, \\
\mathrm{~g} / \mathrm{cm}^{3}\end{array}$ & $\stackrel{\Phi}{(\mathrm{km} / \mathrm{sec})^{2}}$ & $\begin{array}{c}\rho_{c} \\
\mathrm{~g} / \mathrm{cm}^{3}\end{array}$ & $\begin{array}{c}\Phi, \\
(\mathrm{km} / \mathrm{sec})^{2}\end{array}$ \\
\hline 1.000 & $\rho_{0}$ & 0 & 0 & 51.6 & 0 & 65.0 & 3.90 & 49.5 & 4.00 & 62.0 \\
\hline 0.806 & 4.84 & 734 & 708 & 101.1 & 706 & 103.6 & 4.87 & 106.3 & 4.88 & 108.6 \\
\hline 0.801 & 4.87 & 730 & 739 & 102.8 & 738 & 105.0 & 4.87 & 106.0 & 4.87 & 108.3 \\
\hline 0.791 & 4.93 & 831 & 802 & 106.4 & 802 & 107.9 & 4.96 & 113.0 & 4.96 & 114.1 \\
\hline 0.783 & 4.98 & 832 & 856 & 109.4 & 856 & 110.3 & 4.96 & 113.1 & 4.96 & 114.2 \\
\hline 0.783 & 4.98 & 844 & 856 & 109.4 & 856 & 110.3 & 4.97 & 113.9 & 4.97 & 114.9 \\
\hline 0.778 & 5.01 & 844 & 889 & 111.3 & 889 & 111.7 & 4.97 & 113.9 & 4.97 & 114.9 \\
\hline 0.780 & 5.00 & 858 & 878 & 110.7 & 878 & 111.2 & 4.99 & 114.9 & 4.99 & 115.7 \\
\hline 0.778 & 5.01 & 857 & 889 & 111.3 & 889 & 111.7 & 4.99 & 114.8 & 4.98 & 115.6 \\
\hline 0.777 & 5.02 & 941 & 900 & 111.9 & 901 & 112.2 & 5.06 & 120.5 & 5.06 & 120.4 \\
\hline 0.775 & 5.03 & 940 & 911 & 112.5 & 912 & 112.7 & 5.06 & 120.5 & 5.06 & 120.3 \\
\hline 0.759 & 5.14 & 1007 & 1039 & 119.3 & 1039 & 117.9 & 5.11 & 125.0 & 5.11 & 124.0 \\
\hline 0.760 & 5.13 & 1070 & 1027 & 118.7 & 1027 & 117.5 & 5.16 & 129.2 & 5.16 & 127.5 \\
\hline 0.753 & 5.18 & 1063 & 1087 & 121.9 & 1086 & 119.9 & 5.15 & 128.7 & 5.15 & 127.1 \\
\hline 0.754 & 5.17 & 1068 & 1075 & 121.2 & 1074 & 119.4 & 5.16 & 129.0 & 5.16 & 127.4 \\
\hline 0.753 & 5.18 & 1123 & 1087 & 121.9 & 1086 & 119.9 & 5.20 & 132.7 & 5.20 & 130.4 \\
\hline \multicolumn{3}{|c|}{ Standard deviation } & $\begin{array}{c}28.5 \\
3.10 \%\end{array}$ & & $\begin{array}{c}28.7 \\
3.12 \%\end{array}$ & & $\begin{array}{l}0.0245 \\
0.488 \%\end{array}$ & & $\begin{array}{l}0.0247 \\
0.491 \%\end{array}$ & \\
\hline
\end{tabular}

et al. [1967a] and Ahrens et al. [1968]. Preliminary results were given by Anderson and Ahrens [1968]. The present paper simply investigates the difference in the inferred zeropressure properties when corrected, rather than raw, Hugoniot data are used.

In Figures 2 through 18 the region marked $P_{H}$ is the range of metastable Hugoniots that corresponds to the indicated range of assumed zero-pressure densities (the heavy bar above the zero-pressure axis). In some of the figures, the points on the metastable Hugoniot calculated by McQueen et al. [1967a] are shown by horizontal bars or crosses. The heavy bar below the zero-pressure axis is the range of $\rho_{0}$ determined by McQueen et al. [1967a]. The crosses indicate the zero-pressure densities found in the present paper.

The regions on these figures marked $P_{K}$ are $0^{\circ} \mathrm{K}$ isotherms computed by integrating the Mie-Grüneisen equation of state (see, for example, Takeuchi and Kanamori [1966]. The assumed vibrational energy $E_{t_{0}}$ for each material is noted in the legend. The results are not very sensitive to the value of $E_{H 0}$. Again, the range indicated corresponds to the range of initial densities.

\section{Zero-Pressure Properties of High-Pressure Phases}

A wide range of zero-pressure densities and compressibilities satisfy the high-pressure shockwave data equally well. The range can be considerably narrowed by invoking such physical or intuitive constraints as: (1) The density of the high-pressure phase should be greater than the density of the low-pressure phase; (2) the bulk modulus of the high-pressure phase should be greater than the low-pressure phase; $(3)$ the pressure derivative of the bulk modulus is probably less for the more closely packed phase; (4) the bulk modulus probably increases with pressure at sufficiently high pressure. Some of these conditions may be violated, particularly if the high-pressure transformation has not gone to completion.

We invoke the seismic equation of state [Anderson, 1967], an empirical relationship between the zero-pressure density $\rho_{0}$, the mean atomic weight $\bar{M}$, and the slope, at zero pressure, 
of the density-pressure curve $\Phi_{0}=(\partial P / \partial \rho)_{0}$. A least-squares fit to the ultrasonic data of thirty-one minerals and oxides with mean atomic weights between 18.6 and 33.1 yielded

$$
\rho_{0} / \bar{M}=0.048 \Phi_{0}{ }^{0.323}
$$

Alternatively, since $\Phi=K / \rho$, where $K$ is the bulk modulus,

$$
\left(K_{0} / \rho_{0}\right) \sim\left(\rho_{0} / \bar{M}\right)^{3.1}
$$

Figure 1 shows the experimental data that lead to this equation of state. Also shown are the recent X-ray results of Mao [1967]; these values are, of course, measurements of the isothermal bulk modulus. For present purposes we ignore the slight difference between isothermal and adiabatic moduli. The dashed curve is an alternative fit to the data. The slope of this line was taken for convenience as one-third, and its level was adjusted to fit the higherdensity, closely packed structures with compo- sitions most pertinent to the majority of the shock-wave data. The equation of this line is

$$
\rho_{0} / \bar{M}=0.0475 \Phi_{0}{ }^{1 / 3}
$$

for convenience we define

$$
\psi_{0}=\left(\rho_{0} / \bar{M}\right)\left(1 / \Phi_{0}\right)^{1 / 3}
$$

Various other relations of $\rho, \vec{M}$, and $\Phi_{0}$ (or $K_{0}$ ) have also been investigated. Using a different set of data, we find

$$
\rho_{0} / \bar{M}=0.020 K_{0}^{0.28}
$$

is also a good fit to ultrasonic data for rocks with mean atomic weights between 20.4 and 24.3. For comparison purposes we tabulate

$$
\psi_{0}{ }^{2}=\left(\rho_{0} / \bar{M}\right) K_{0}{ }^{-0.28}
$$

in Table 1. In general, when $\psi_{0}$ is near 0.0475 , $\psi_{0}^{\prime}$ is near 0.020 .

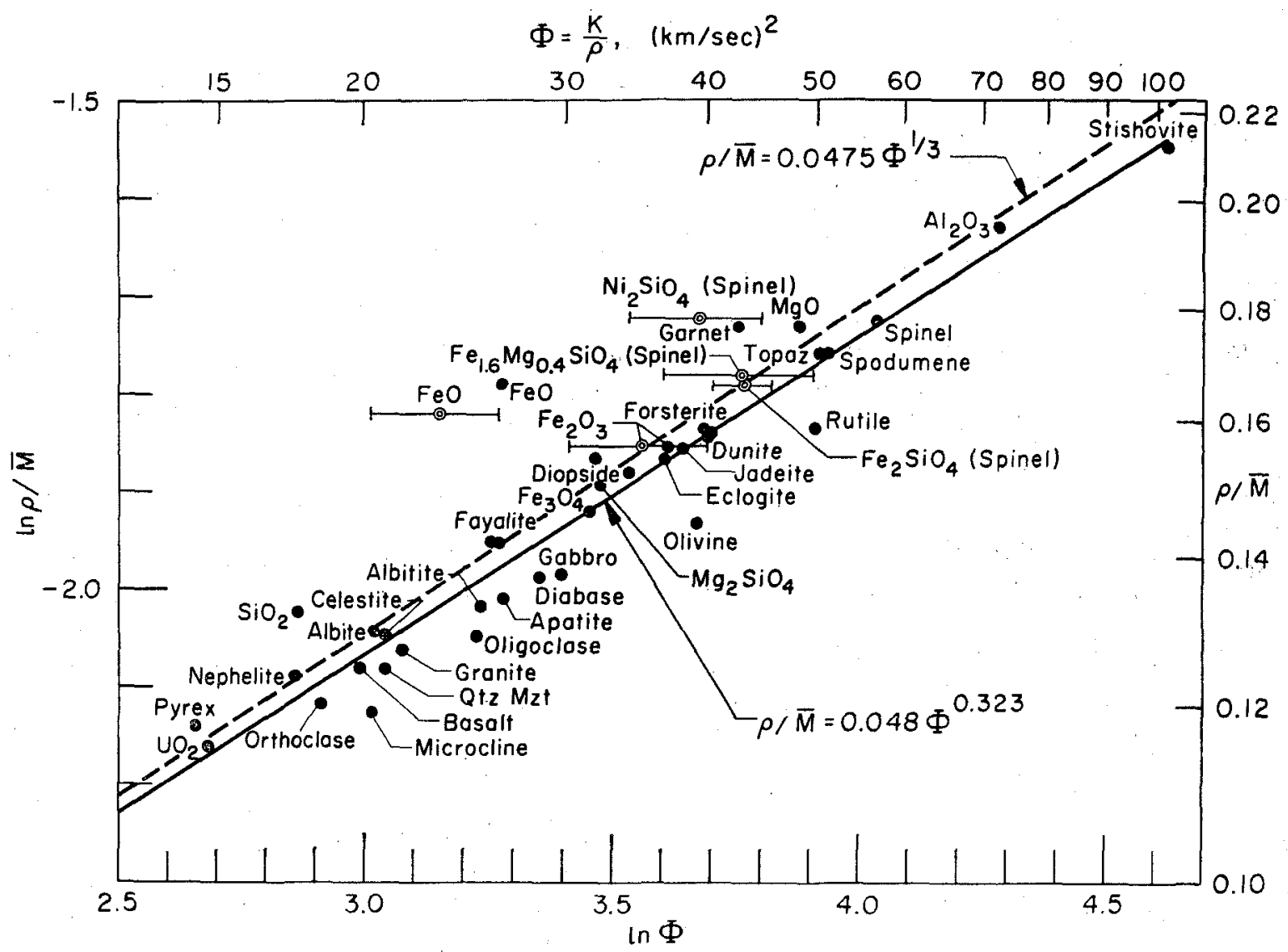

Fig. 1. $\phi_{0}=(d P / d \rho)_{0}$ versus $\rho_{0} / \bar{M}$ for oxides and silicates. Data from Anderson [1967], Mao [1967], and Drickamer et al. [1966]. 


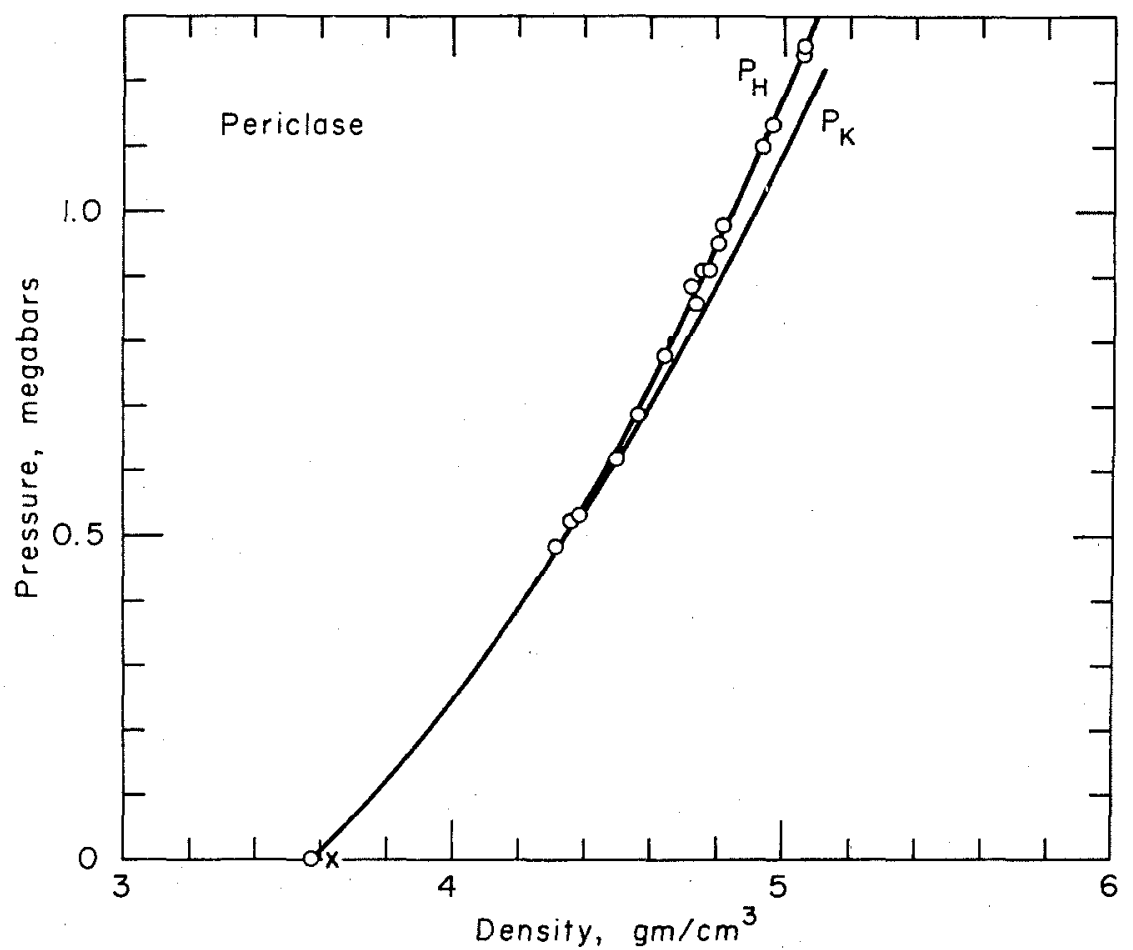

Fig. 2. Pressure-density Hugoniot for $\mathrm{MgO} . P_{\boldsymbol{B}}$ is fitted Hugoniot; $P_{\boldsymbol{K}}$ is derived isotherm. The vibrational energy $E_{H 0}$ used in the calculation of the isotherm is $1.3 \times 10^{\theta} \mathrm{ergs} / \mathrm{g}$.

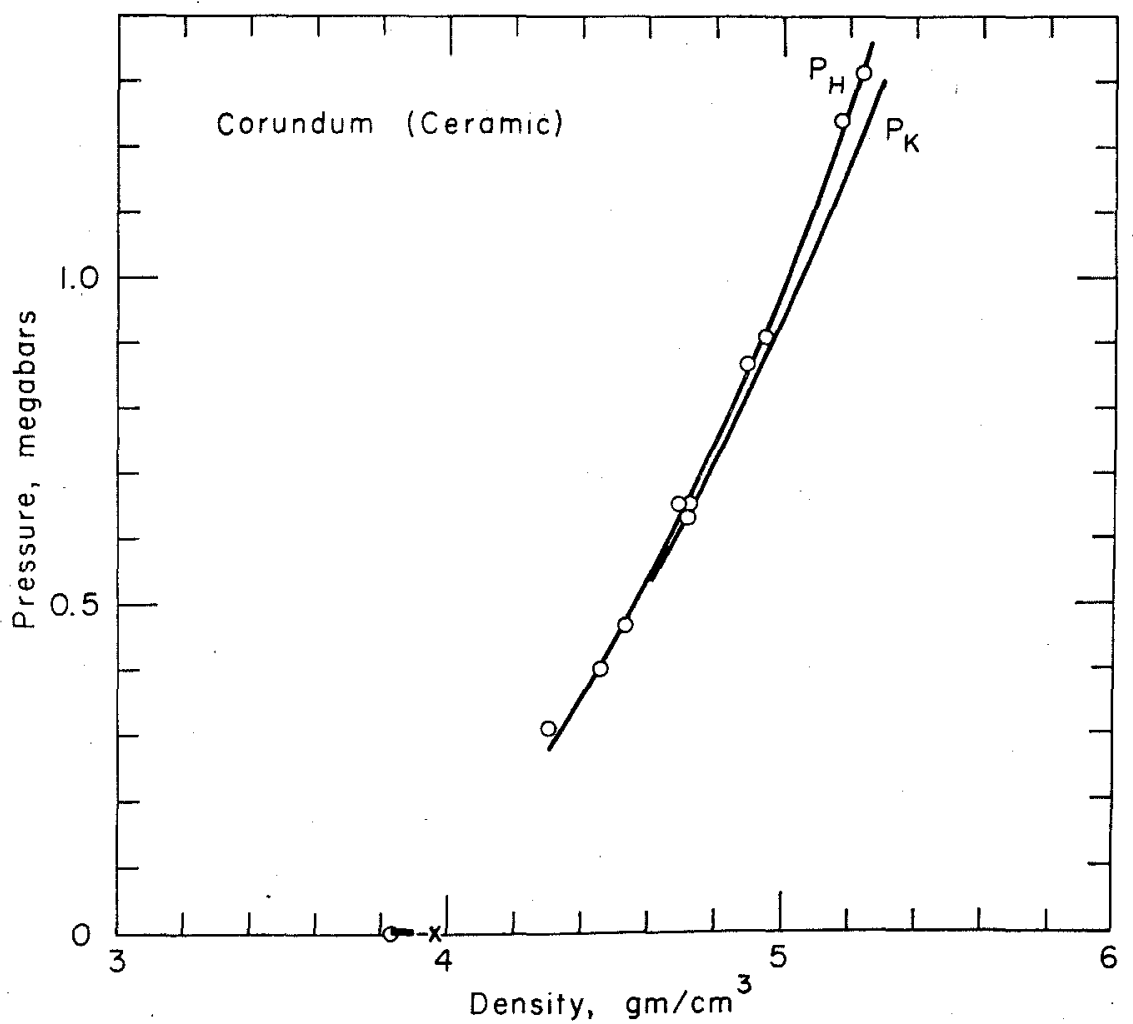

Fig. 3. Pressure-density Hugoniot for ceramic $\mathrm{Al}_{2} \mathrm{O}_{3}$. The heavy horizontal bar on the zero-pressure axis is the range of $\rho_{0}$ for which linear $U_{\theta}-U_{p}$ fits have been obtained (Table 3 ). The cross is the zero-pressure density satisfying $\psi_{0}=0.0475 . E_{H 0}$ is taken as $1.0 \times 10^{\circ} \mathrm{ergs} / \mathrm{g}$. 


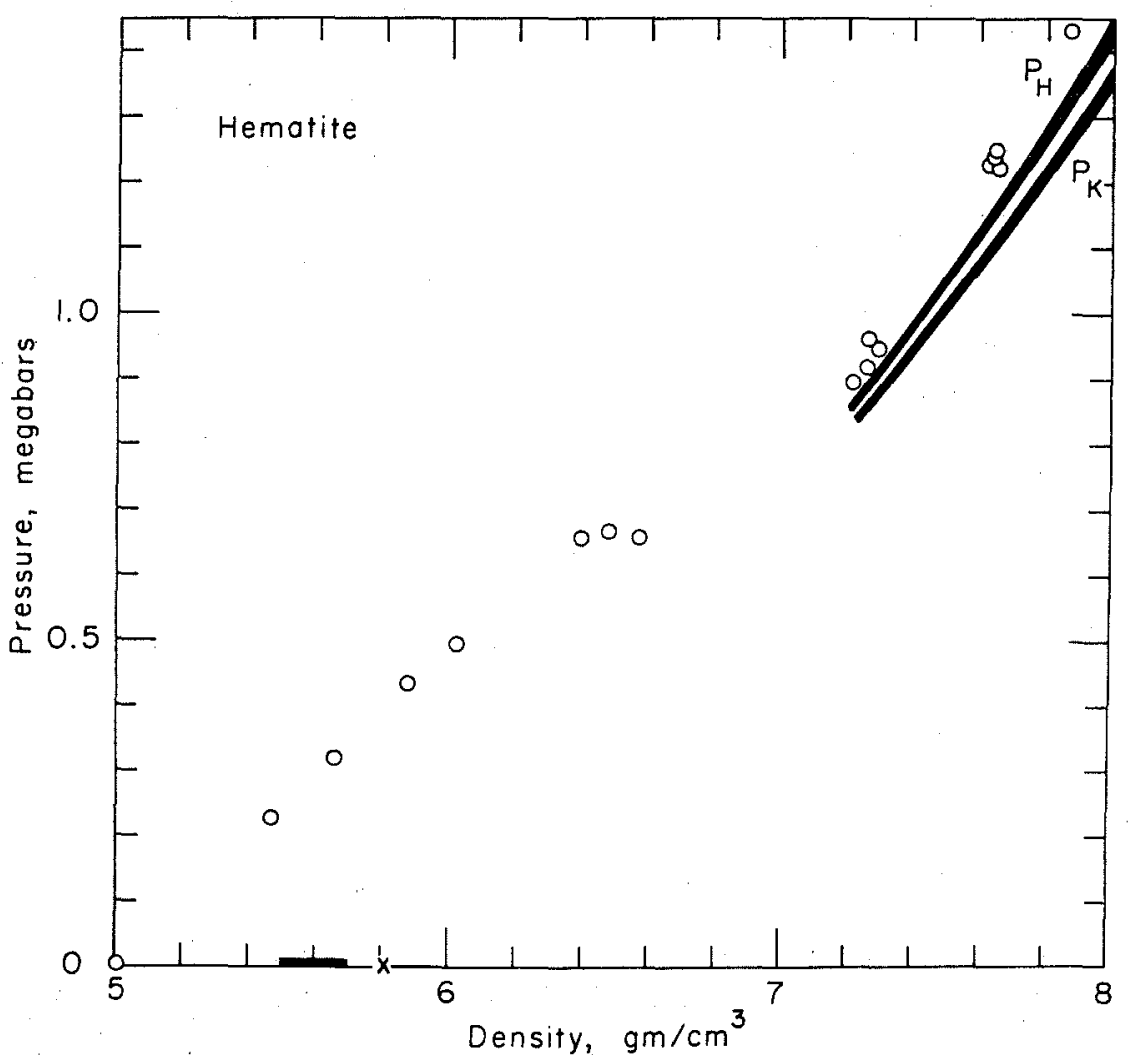

Fig. 4. Pressure-density Hugoniot for $\mathrm{Fe}_{2} \mathrm{O}_{3}$ and derived metastable Hugoniot $P_{H}$ and isotherm $P_{K}$ for zero-pressure density range indicated. In this and following figures we are concerned only with the high-pressure data. $E_{H 0}=10^{9} \mathrm{ergs} / \mathrm{g}$.

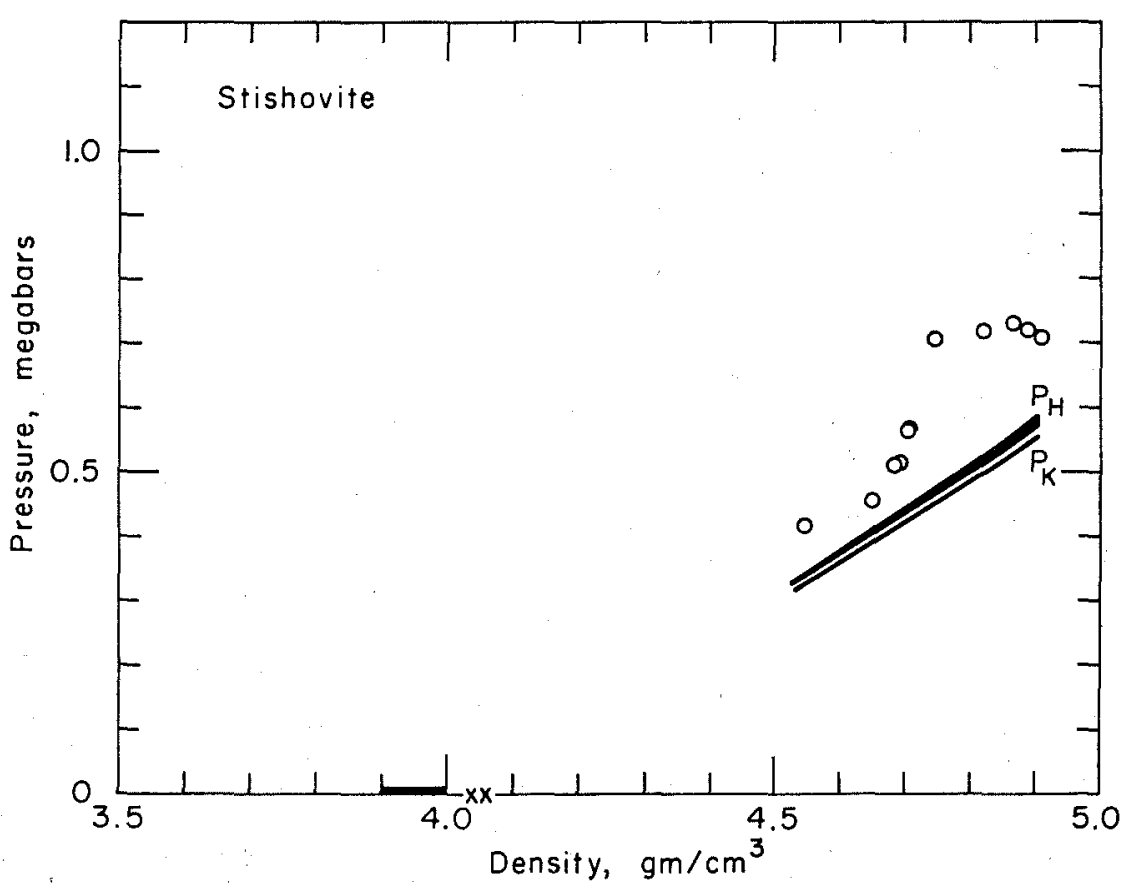

Fig. 5. Pressure-density Hugoniot for high-pressure phase of $\mathrm{SiO}_{2}, E_{H 0}=10^{\circ} \mathrm{ergs} / \mathrm{g}$. 


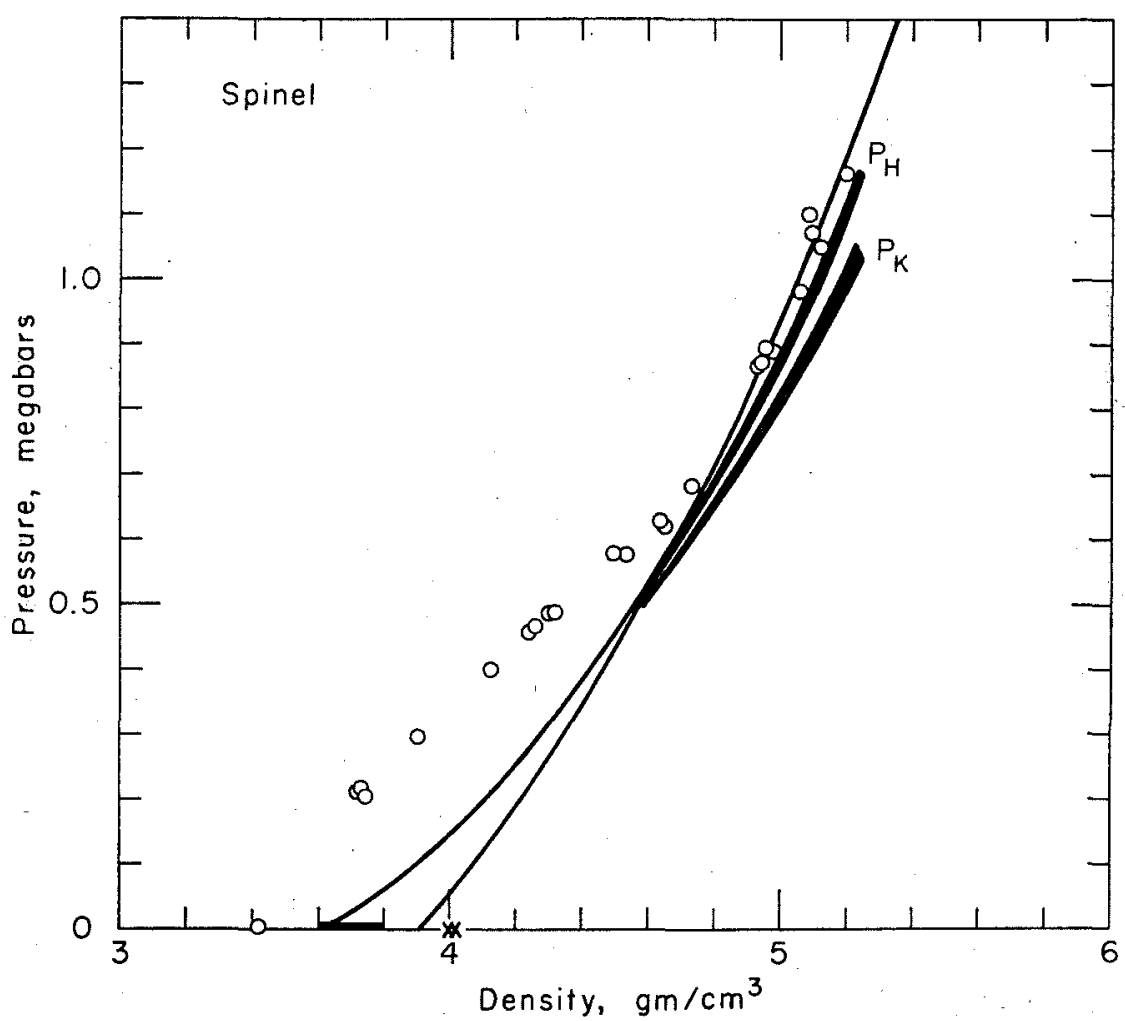

Fig. 6. Pressure-density Hugoniot for $\mathrm{MgAl}_{2} \mathrm{O}_{4}$ and derived metastable Hugoniot and isotherm $\left(E_{z 0}=1.3 \times 10^{\circ} \mathrm{ergs} / \mathrm{g}\right)$. Also shown are least-square fits to the high-pressure data of Murnaghan equations for two assumed starting densities. This illustrates the difficulty of finding $\rho_{0}$ from the shock-wave data alone.

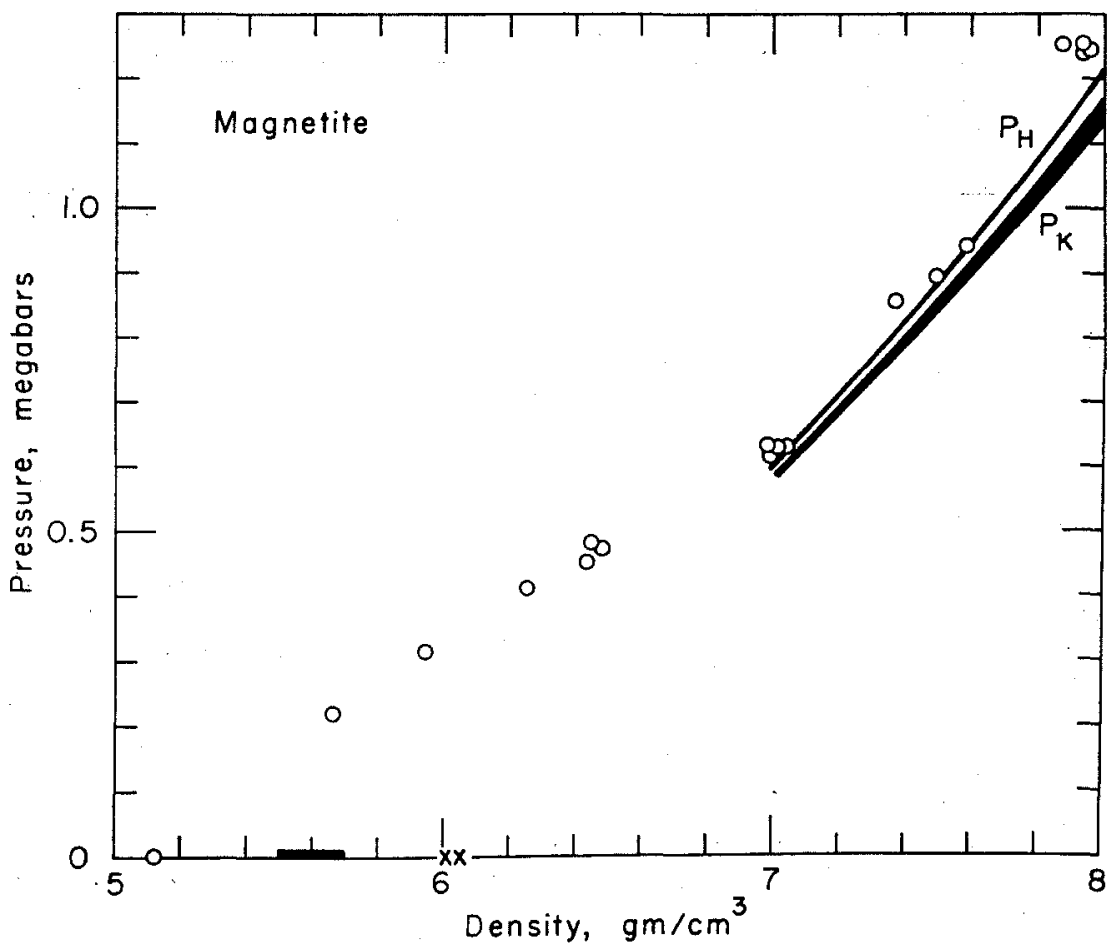

Fig. 7. Pressure-density Hugoniot for $\mathrm{Fe}_{3} \mathrm{O}_{4}$ and derived metastable Hugoniot and isotherm. $E_{H 0}=10^{\circ} \mathrm{ergs} / \mathrm{g}$. 


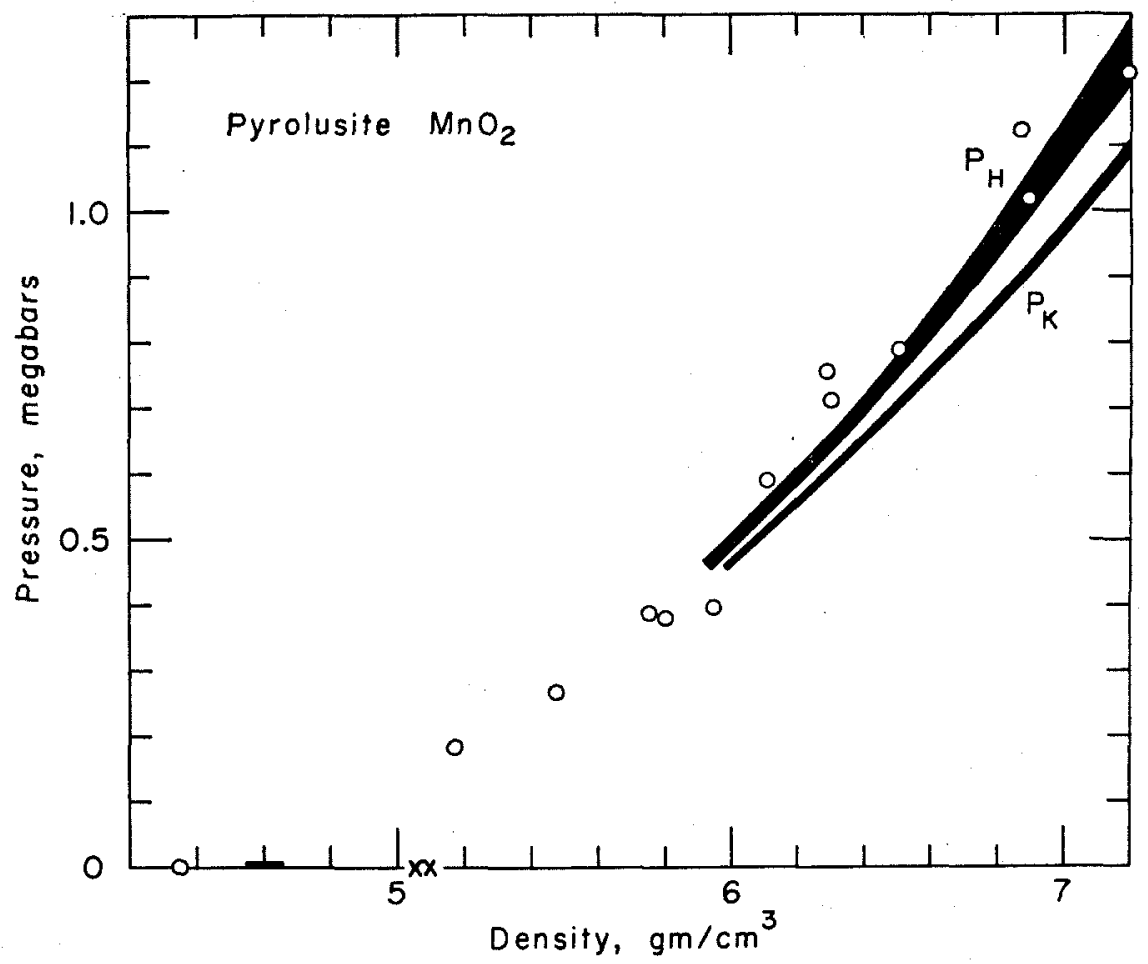

Fig. 8. Pressure-density Hugoniot for $\mathrm{MnO}_{2}$ and derived Hugoniot and isotherm ( $E_{H 0}=$ $1.3 \times 10^{\circ} \mathrm{ergs} / \mathrm{g}$ ), assuming no phase change.

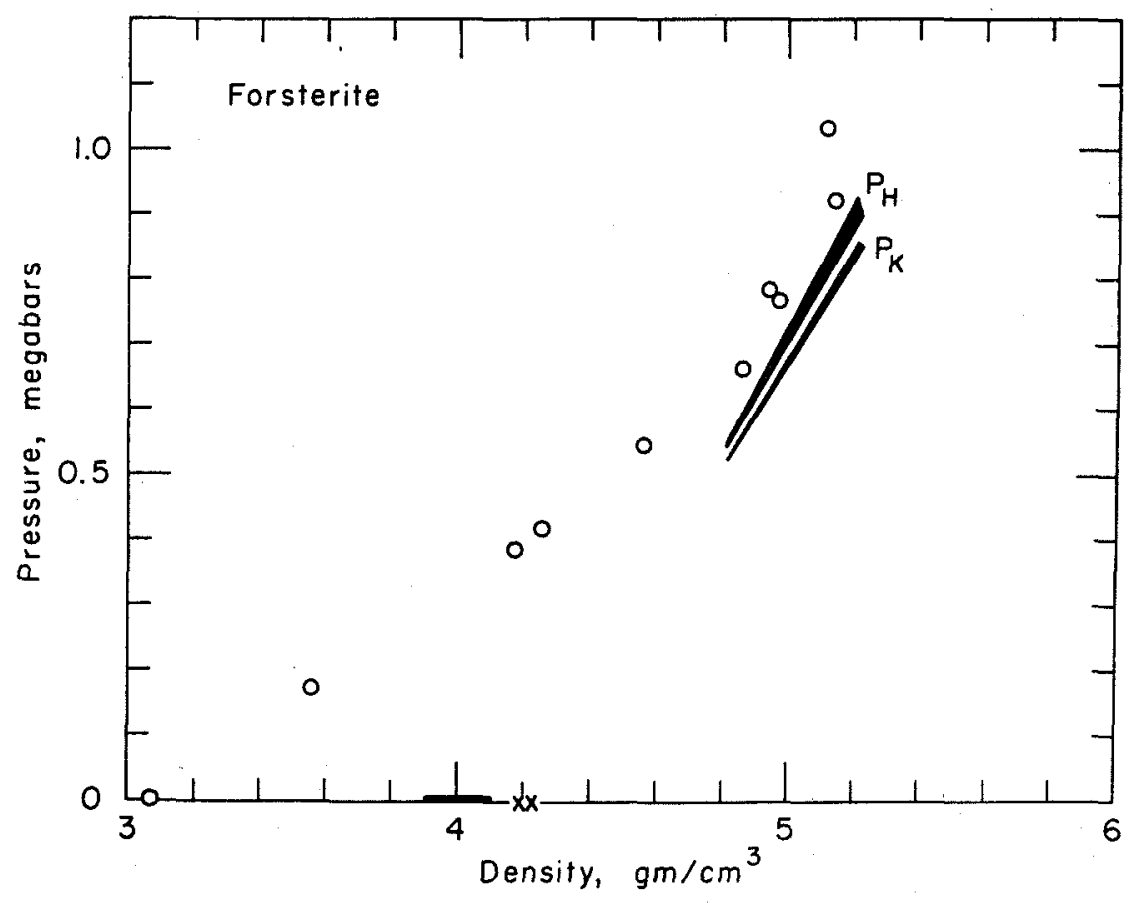

Fig. 9. Pressure-density Hugoniot for ceramic $\mathrm{Mg}_{2} \mathrm{SiO}_{4}$ and derived metastable Hugoniot and isotherm $\left(E_{E 0}=10^{\circ} \mathrm{ergs} / \mathrm{g}\right)$ for high-pressure phase. 


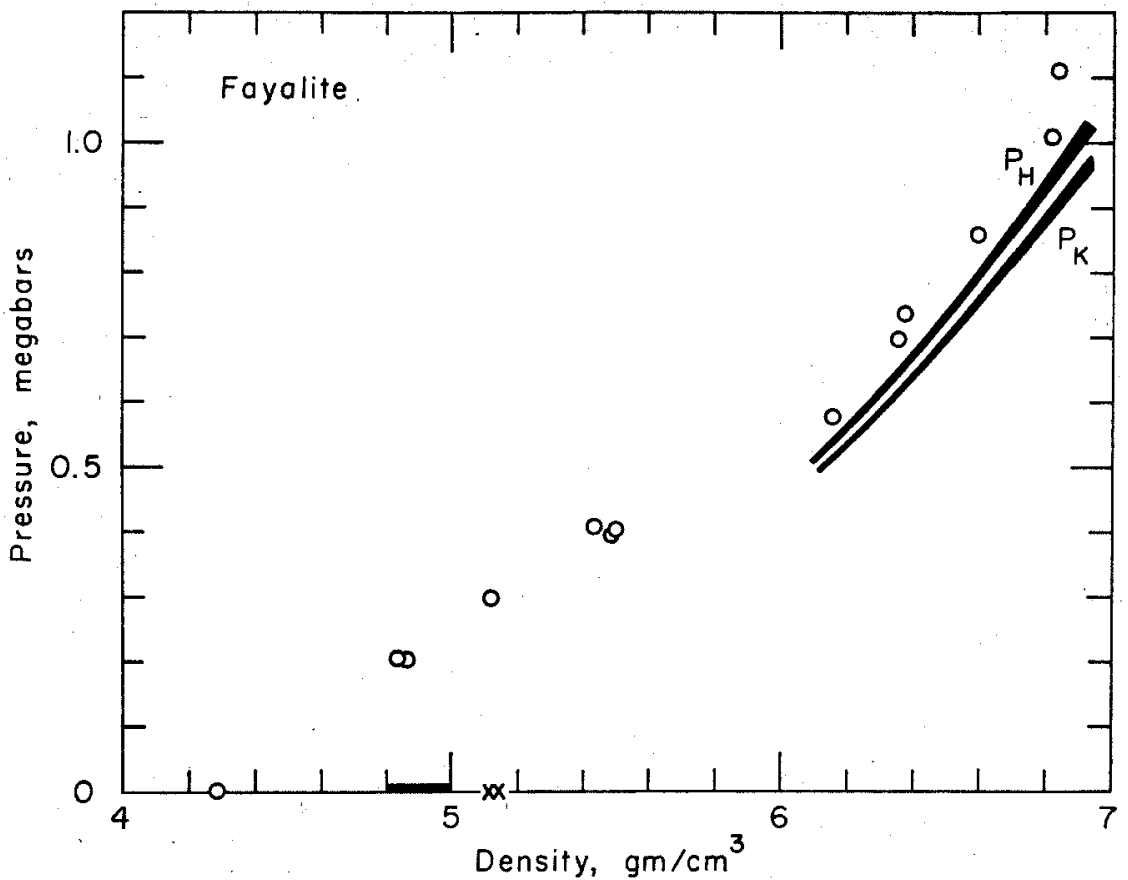

Fig. 10. Pressure-density Hugoniot for Rockport fayalite and derived metastable Hugoniot and isotherm for indicated range of $\rho_{0} . E_{H 0}=10^{\circ} \mathrm{ergs} / \mathrm{g}$.

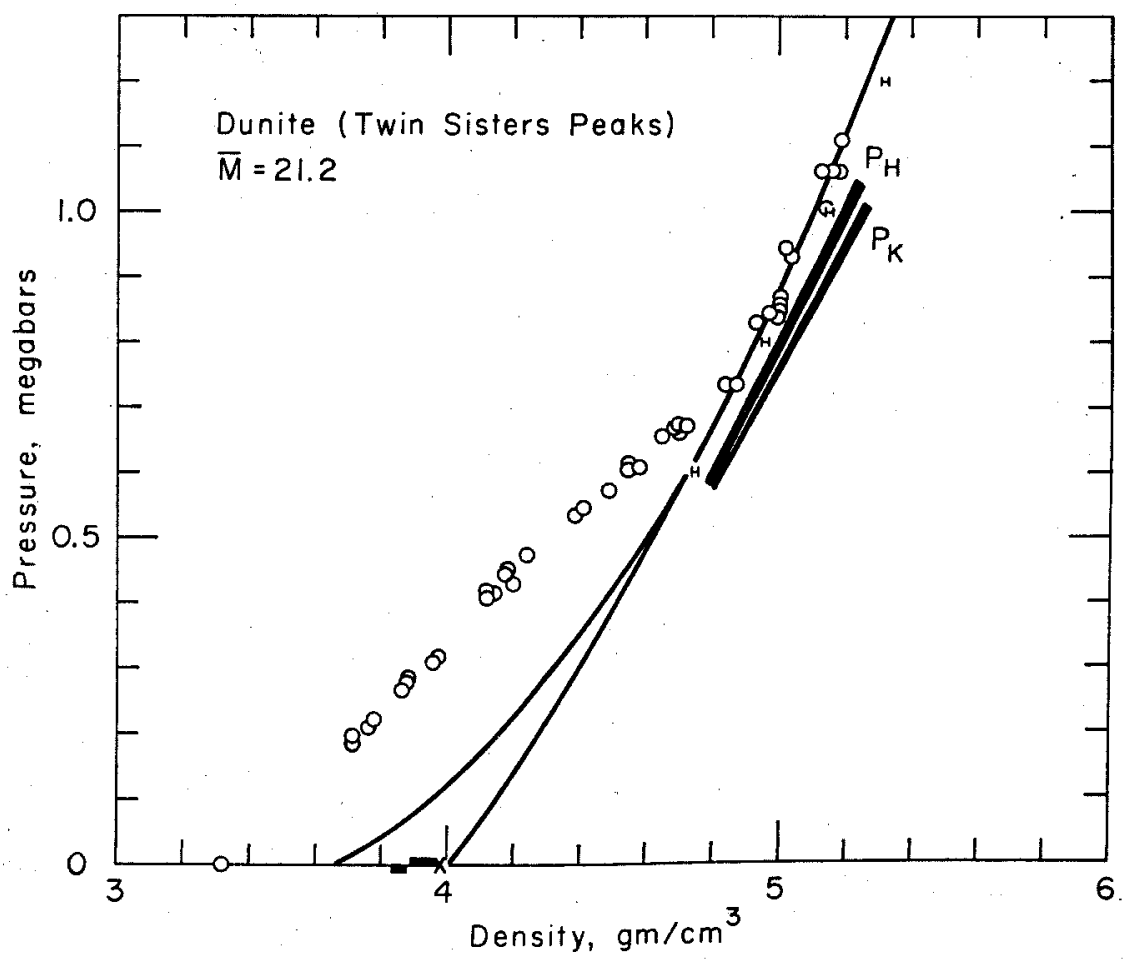

Fig. 11. Pressure-density Hugoniot for Twin Sisters dunite and derived metastable Hugoniot and isotherm for indicated range of $\rho_{0}$. The heavy bar below the $P(0)$ axis is the range of $\rho_{0}$ estimated by $M c Q u e e n$ et al. [1967]; the cross is the $\rho_{0}$ estimated in this paper. Also shown are Birch-Murnaghan fits to the high-pressure data for two different $\rho_{0}$. The symbol $(H)$ indicates the range of metastable Hugoniots calculated by $M c Q u e e n$ et al. [1967]. $E_{B 0}=1.3 \times 10^{\circ}$ ergs/g. 


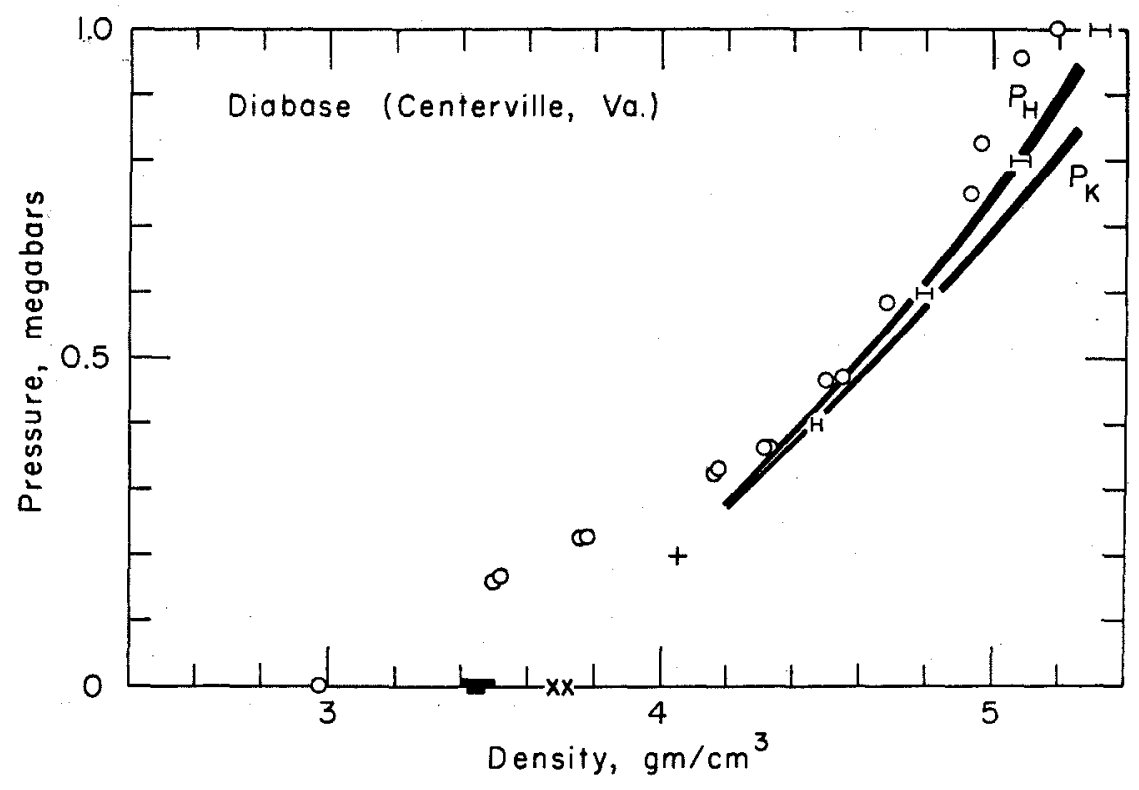

Fig. 12. Pressure-density Hugoniot for diabase from Centreville, Virginia. $E_{r 0}$ for diabase is taken as $10^{\circ} \mathrm{ergs} / \mathrm{g}$.

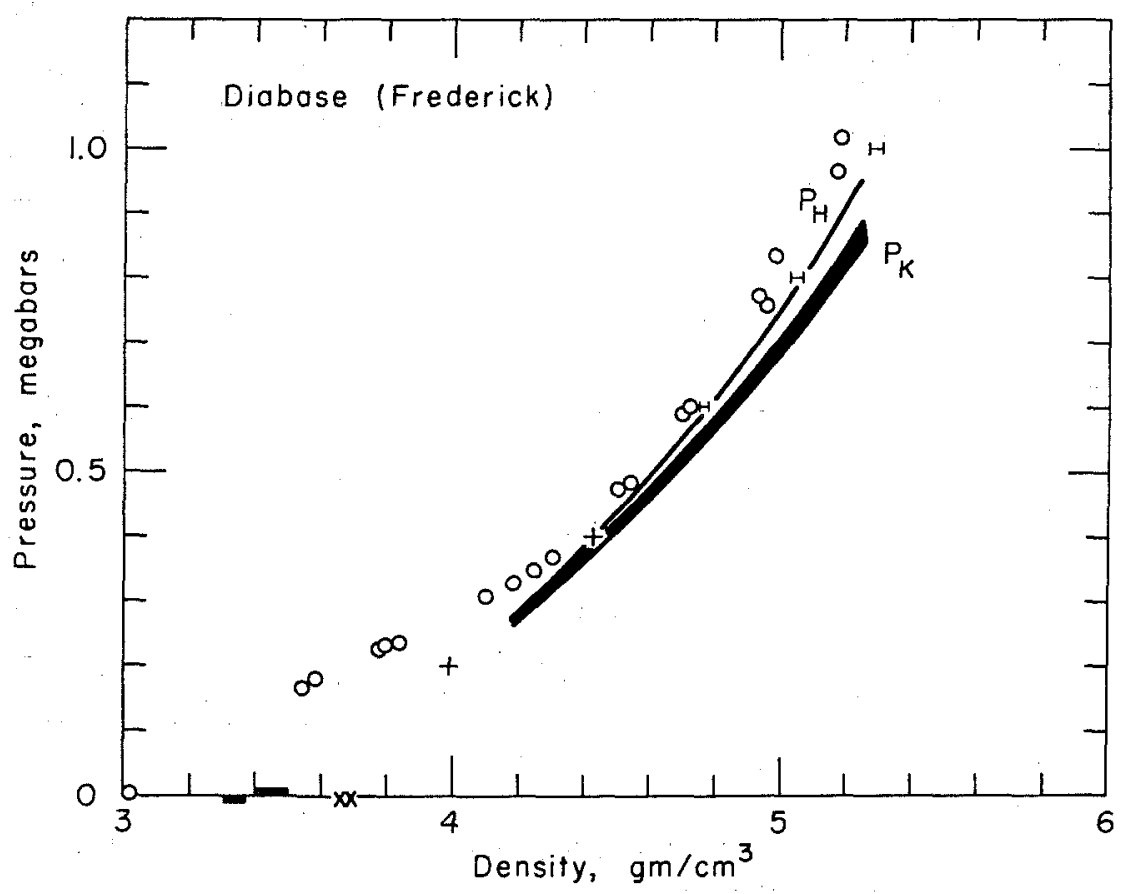

Fig. 13. Pressure-density Hugoniot for diabase from Frederick, Maryland: 


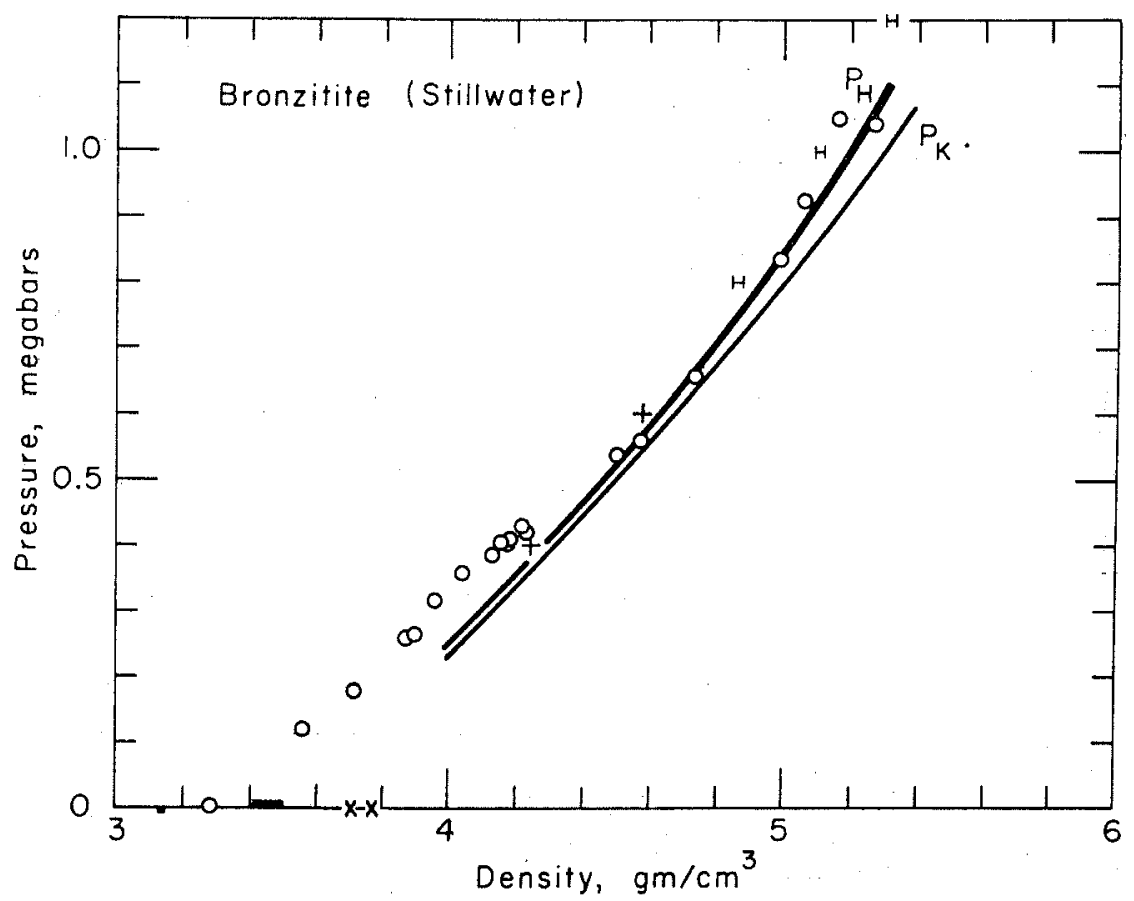

Fig. 14. Pressure-density Hugoniot for bronzitite from the Stillwater Complex. $E_{H 0}=1.5 \times$ $10^{9} \mathrm{ergs} / \mathrm{g}$.

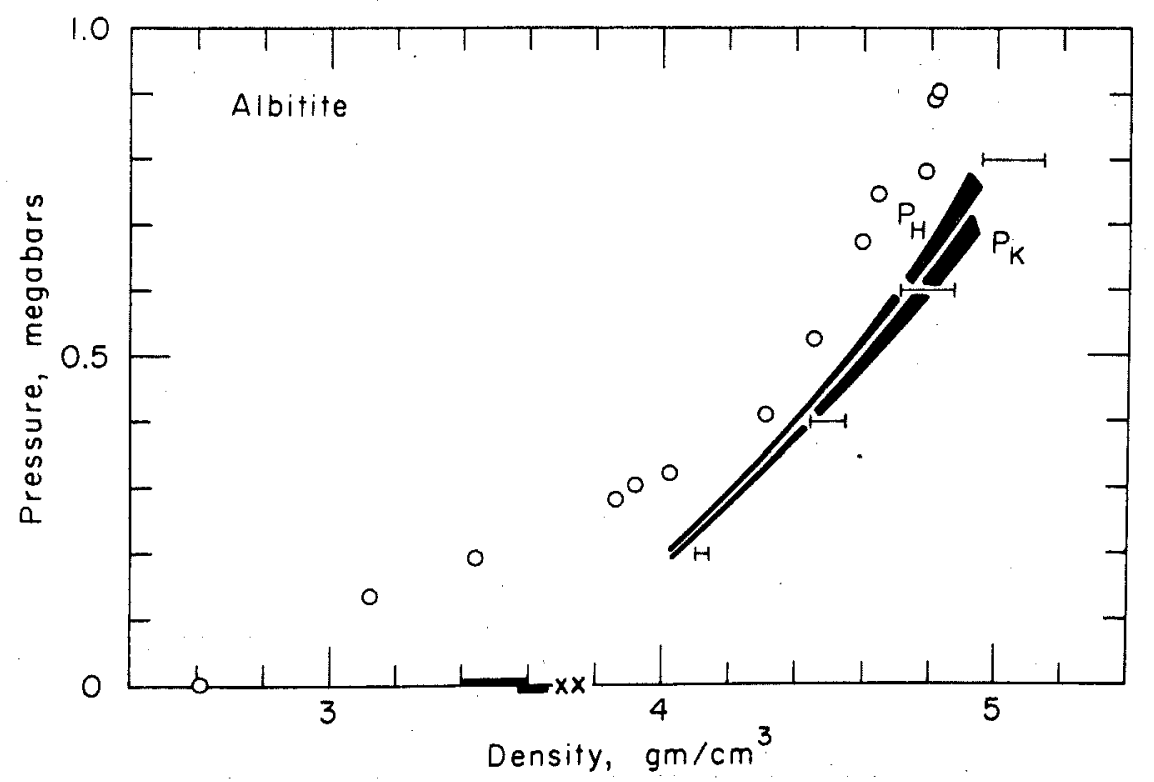

Fig. 15. Pressure-density Hugoniot for albitite. $E_{H 0}=1.5 \times 10^{9} \mathrm{ergs} / \mathrm{g}$. 


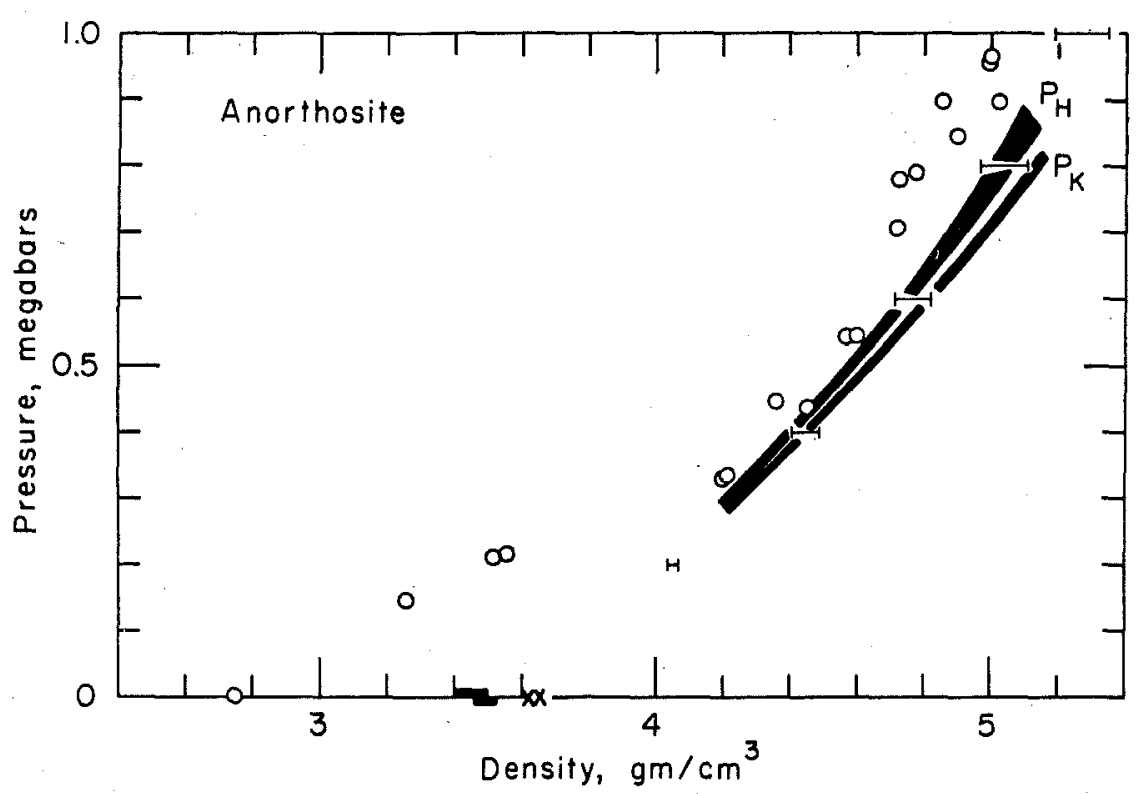

Fig. 16. Pressure-density Hugoniot for anorthosite. $E_{H 0}=1.5 \times 10^{\circ} \mathrm{ergs} / \mathrm{g}$.

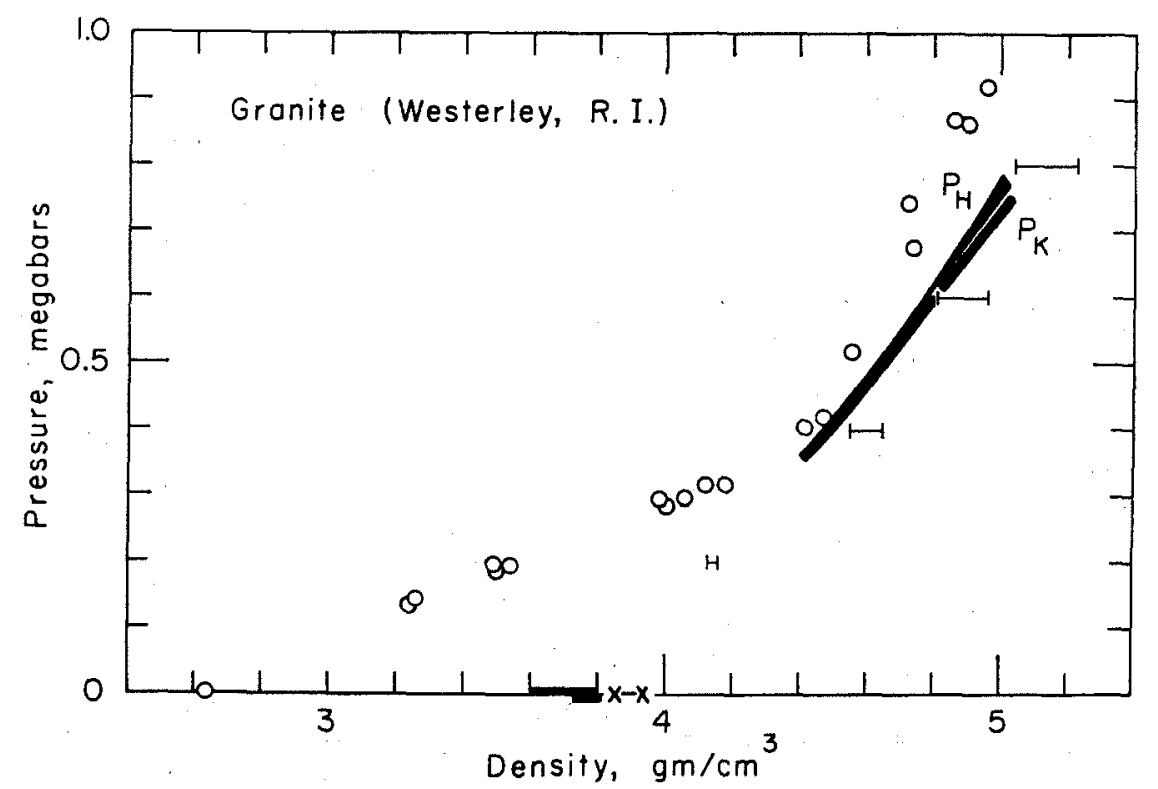

Fig. 17. Pressure-density Hugoniot for granite. $E_{H 0}=10^{9} \mathrm{ergs} / \mathrm{g}$. 


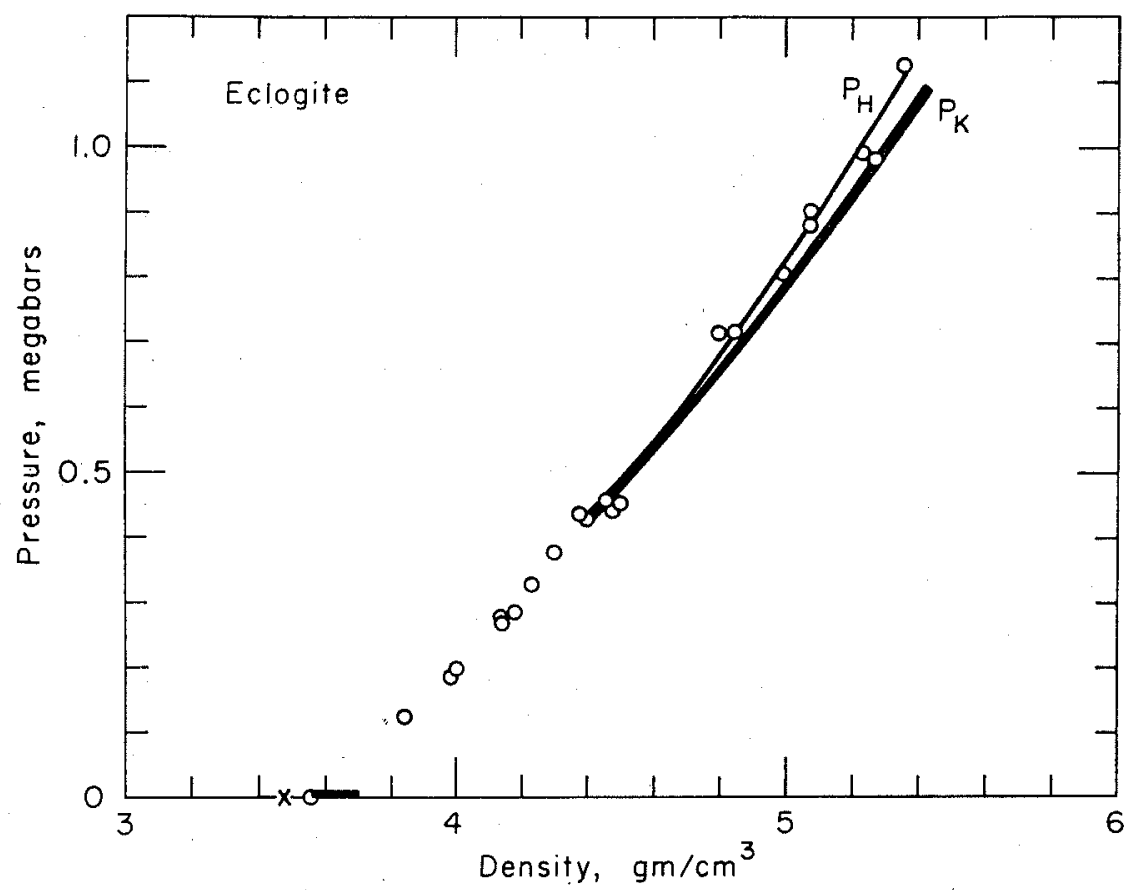

Fig. 18. Pressure-density Hugoniot for eclogite. Note that the high-pressure data extrapolate to a zero-pressure density that is less than the starting density, indicating that the transformation is probably not complete. $E_{H 0}=10^{\natural} \mathrm{ergs} / \mathrm{g}$.

Table 4 gives $\bar{M}, \rho_{0}, \Phi_{0}$, and $\psi_{0}$ for the lowpressure phases of the materials used in the present study and for some other oxides and silicates. For the rocks the presence of pores and cracks complicates the interpretation of both the density and the $\Phi_{0}$ and introduces a scatter into the $(\rho / \bar{M})-\Phi_{0}$ relationship. The parameter $\left(\rho_{0} / \bar{M}\right) \Phi_{0}^{-1 / 3}$ is anomalously low for $\mathrm{CaO}$ and slightly lower for the $\mathrm{CaO}$-rich rocks albitite, anorthosite, and diabase than it is for the remaining rocks. The eclogites are, however, also rich in $\mathrm{CaO}$, but the Sunnmore, Norway, sample $(\bar{M}=22.2)$ has a higher than average $\psi_{0}$, whereas the Healdsburg, California, sample has a near normal value. We will adopt the value of $\psi_{0}=0.0475$ as being fairly representative and will assume that the zero-pressure properties of the high-pressure phases satisfy (6). An alternative approach would be to assume that the relative changes in the density and $\Phi$ between the low-pressure and high-pressure forms of a given material are related by

$$
\Delta \rho_{0} / \rho_{0}=1 / 3\left(\Delta \Phi_{0} / \Phi_{0}\right)
$$

A third approach would be to adopt the Murnaghan parameter $n$ or the Birch-Murnaghan parameter $\xi$ determined for, say, $\mathrm{MgO}$, which does not undergo a phase change, and then to determine $\rho_{0}$ and $K_{0}$ from the shockwave data. This method would be equivalent to the assumption that $(d K / d P)_{0}$ is a universal parameter.

Table 5 summarizes the estimated zero-pressure, high-temperature parameters of the shock induced high-pressure phases with the constraint that the density and $\phi_{0}$ of the highpressure phases satisfy $\psi_{0}=0.0475$. Tabulated, for comparison, are the densities that would result if the rocks were made of the pure oxides $\mathrm{MgO}, \mathrm{FeO}, \mathrm{Al}_{2} \mathrm{O}_{3}, \mathrm{NaO}$, and $\mathrm{SiO}_{2}$ (stishovite). This is simply a convenient high-pressure datum to which the densities of the high-pressure phases can be. referred. The densities of the oxide mixtures are appropriate for room temperature conditions, and the estimated densities of the high-pressure phases are appropriate for temperatures of the order of $1000^{\circ} \mathrm{K}$ and greater. The individual materials will be discussed in the following sections.

Except for eclogite, the inferred zero-pressure densities and $\Phi$ of the high-pressure phases are greater than for the low-pressure phases. The higher-pressure data for the eclogite is probably in a mixed phase region. If eclogite 
TABLE 4. Zero-Pressure Parameters of LowPressure Phases

\begin{tabular}{|c|c|c|c|c|}
\hline Material & $\bar{M}$ & $\rho_{0}$ & $\Phi_{0}$ & $\left(\rho_{0} / \bar{M}\right) \Phi_{0}^{-1}$ \\
\hline \multicolumn{5}{|c|}{ Ultrasonic Results* } \\
\hline Jadeite & 20.2 & 3.33 & 41.1 & 0.0478 \\
\hline Albitite & 20.4 & 2.61 & 26.5 & 0.0429 \\
\hline Granite & 20.6 & 2.63 & 20.2 & 0.0468 \\
\hline Bronzitite & 20.7 & 3.30 & 34.2 & 0.0491 \\
\hline Bronzitite & 20.7 & 3.28 & 30.2 & 0.0509 \\
\hline Anorthosite & 21.0 & 2.72 & 30.7 & 0.0414 \\
\hline Dunite & 21.2 & 3.32 & 38.4 & 0.0464 \\
\hline Diabase & 21.5 & 3.01 & 26.6 & 0.0469 \\
\hline Diabase & 21.8 & 2.99 & 27.1 & 0.0456 \\
\hline Eclogite & 22.2 & 3.55 & 26.4 & 0.0535 \\
\hline Eclogite & 22.3 & 3.42 & 34.5 & 0.0471 \\
\hline Dunite & 25.1 & 3.79 & 32.8 & 0.0472 \\
\hline \multicolumn{5}{|c|}{ Ultrasonic Results $\dagger$} \\
\hline $\mathrm{Al}_{2} \mathrm{O}_{3}$ & 20.03 & 3.97 & 63.1 & 0.0498 \\
\hline $\mathrm{MgO} \cdot 2.61 \mathrm{Al}_{2} \mathrm{O}_{3} \S$ & 20.07 & 3.62 & 55.2 & 0.0473 \\
\hline $\mathrm{Mg}_{2} \mathrm{SiO}_{4}$ & 20.10 & 3.02 & 32.0 & 0.0473 \\
\hline $\mathrm{MgO}$ & 20.16 & 3.58 & 44.6 & 0.0501 \\
\hline $\mathrm{MgO}$ & 20.16 & 3.58 & 47.3 & 0.0491 \\
\hline 'Garnet' & 23.79 & 4.16 & 42.2 & 0.0502 \\
\hline $\mathrm{ZnO}$ & 40.69 & 5.62 & 24.7 & 0.0474 \\
\hline \multicolumn{5}{|c|}{$X$-Ray Results $\ddagger$} \\
\hline $\mathrm{MgO}$ & 20.16 & 3.58 & 49.7 & 0.0483 \\
\hline $\mathrm{Fe}_{1.6} \mathrm{Mg}_{0 .} \mathrm{SiO}_{4} \S$ & 27.31 & 4.60 & 43.1 & 0.0480 \\
\hline $\mathrm{CaO}$ & 28.04 & 3.35 & 33.5 & 0.0371 \\
\hline $\mathrm{Fe}_{2} \mathrm{SiO}_{4} \S$ & 29.11 & 4.85 & 43.1 & 0.0475 \\
\hline $\mathrm{Ni}_{2} \mathrm{SiO}_{4} \S$ & 29.93 & 5.35 & 39.5 & 0.0525 \\
\hline $\mathrm{Fe}_{2} \mathrm{O}_{3}$ & 33.08 & 5.20 & 35.2 & 0.0480 \\
\hline 'FeO' & 34.53 & 5.75 & 26.8 & 0.0556 \\
\hline ' $\mathrm{FeO}$ ' & 35.13 & 5.69 & 23.4 & 0.0566 \\
\hline $\mathrm{MnO}$ & 35.47 & 5.37 & 26.8 & 0.0504 \\
\hline $\mathrm{NiO}$ & 37.35 & 6.81 & 29.2 & 0.0592 \\
\hline $\mathrm{CaO}$ & 37.47 & 6.44 & 29.6 & 0.0556 \\
\hline $\mathrm{CdO}$ & 64.20 & 8.24 & 13.1 & 0.0545 \\
\hline
\end{tabular}

\footnotetext{
* Compiled by McQueen et al. [1967a], adiabatic $\phi_{0}$.

† Compiled by O. L. Anderson (private communication, 1967), isothermal $\Phi_{0}$.

$\ddagger$ Drickamer et al. [1966] and Mao [1967], isothermal $\Phi_{0}$.

$\S$ Spinel structure.
}

is ignored, the range of $\Phi_{0}$ for the high-pressure phases is 45 to 85 , compared with the range of 14 to 40 for the open structure silicates, and 31 to 63 for the low-pressure but closely packed oxides.

The Murnaghan parameter $n$ and the BirchMurnaghan parameter $\xi$ for the high-pressure phases constrained by $\psi_{0}=0.0475$ can be estimated from the results in Table 1 . Both of these parameters are related to the pressure derivative of the bulk modulus at zero pressure

$$
\begin{aligned}
& n=(d K / d P)_{0} \\
& \xi=1 / 4\left[12-3(d K / d P)_{0}\right]
\end{aligned}
$$

and, with Slater's assumptions, to the Grüneisen ratio $\gamma$

$$
\begin{aligned}
& n=2 \gamma+1 / 3 \\
& \xi=1 / 4[11-6 \gamma]
\end{aligned}
$$

The Grüneisen ratio is a small number that ranges roughly from 1 to 2 . The range of the parameter $n$ is therefore about 2.3 to 4.3 and the range of $\xi$ is about -0.25 to +1.25 .

Estimates of $K_{0}, \xi, n, \gamma$, and $\Phi_{0}$ from the present work and from ultrasonic and $\mathrm{X}$-ray measurements are given in Table 6 . The data are of variable quality, but several trends seem to have been established. The related parameters $n, \xi$, and $\gamma$ seem to depend both on composition and on crystal structure. The parameter $n$ is quite high for open packed structures such as quartz (6.4), forsterite (4.8), and simple cubic compounds $\mathrm{CsCl}$ (4.8), $\mathrm{TlCl}$ (6.0), and $\mathrm{NH}_{4} \mathrm{Cl}$ (5.5). It is 4.19 for spinel, and ranges from 2 to 4 for the post-spinels and oxides.

There is a suggestion that in a given crystal structure $n$ and $\gamma$ decrease and $\xi$ increases on iron substitution. This is particularly evident in the post-spinel group where forsterite is the sole exception. The zero-pressure density of the high-pressure form of forsterite is $37 \%$ greater than the starting density, compared with the 20-23\% density increases for fayalite and the dunites. Forsterite is apparently going to a different, denser phase than other olivine-rich materials; this is consistent with the lower $n$ value.

\section{Discussion of Individual Materials}

Figures 2 through 18 show the raw Hugoniot data (open circles); the computed metastable Hugoniots (heavy curves labeled $P_{H}$ ), and the computed isotherms (heavy curves labeled $P_{E}$ ) for the range of $\rho_{0}$ indicated by the heavy bar above the $P=0$ line; the zero-pressure density of the high-pressure phase satisfying $\psi_{0}=$ 0.0475 (shown as crosses); the range of metastable Hugoniot's (shown as horizontal bars) 
TABLE 5. Zero-Pressure Parameters for Raw and Metastable Hugoniot Data

All solutions are for $\psi=0.0475$.

\begin{tabular}{|c|c|c|c|c|c|c|c|c|}
\hline Material & $\begin{array}{c}\bar{M} \\
\text { grams }\end{array}$ & $\begin{array}{c}\text { Sample } \\
\text { Density, } \\
\text { g/ } / \mathrm{cm}^{3}\end{array}$ & $\begin{array}{l}\text { Theoret- } \\
\text { ical } \\
\text { Density } \\
\mathrm{g} / \mathrm{cm}^{3}\end{array}$ & $\begin{array}{c}\text { Low- } P \\
\text { Phase } \Phi_{0}, \\
(\mathrm{~km} / \mathrm{sec})^{2}\end{array}$ & $\begin{array}{l}\text { Oxides } \\
\text { Density, } \\
\mathrm{g} / \mathrm{cm}^{3}\end{array}$ & $\begin{array}{c}\text { High-P } \\
\text { Phase } \\
\text { Density, } \\
\text { g/cm }{ }^{3}\end{array}$ & $\begin{array}{l}\text { High- } P \\
\text { Phase } \Phi_{0} \\
(\mathrm{~km} / \mathrm{sec})^{2}\end{array}$ & $\begin{array}{c}\text { High- } P \\
\text { Phase } \\
\partial K / \partial P\end{array}$ \\
\hline Albitite & 20.4 & 2.61 & & 25 & 3.85 & $\begin{array}{l}3.70^{*} \\
3.75\end{array}$ & $\begin{array}{l}56^{*} \\
58\end{array}$ & $\begin{array}{l}3.75^{*} \\
2.43\end{array}$ \\
\hline Anorthosite & 21.0 & 2.75 & & 30 & 3.91 & $\begin{array}{l}3.62^{*} \\
3.65\end{array}$ & $\begin{array}{l}48^{*} \\
49\end{array}$ & $\begin{array}{l}3.50^{*} \\
2.53\end{array}$ \\
\hline Bronzitite & 20.7 & 3.28 & & 33 & 4.08 & $\begin{array}{l}3.70^{*} \\
3.77\end{array}$ & $\begin{array}{l}53^{*} \\
56\end{array}$ & $\begin{array}{l}2.82^{*} \\
2.34\end{array}$ \\
\hline Corundum†̣ & 20.40 & 3.83 & 3.99 & 63 & & $3.96^{*}$ & $68^{*}$ & $3.96^{*}$ \\
\hline $\begin{array}{l}\text { Diabase } \\
\text { (Centreville) }\end{array}$ & 21.8 & 2.98 & & 27 & 4.01 & $\begin{array}{l}3.67^{*} \\
3.71\end{array}$ & $\begin{array}{l}45^{*} \\
46\end{array}$ & $\begin{array}{l}3.35^{*} \\
2.64\end{array}$ \\
\hline $\begin{array}{l}\text { Diabase } \\
\text { (Frederick) }\end{array}$ & 21.5 & 3.02 & & 27 & 4.08 & $\begin{array}{l}3.66^{*} \\
3.69\end{array}$ & $\begin{array}{l}46^{*} \\
47\end{array}$ & $\begin{array}{l}3.13^{*} \\
2.51\end{array}$ \\
\hline $\begin{array}{l}\text { Dunite } \\
\text { (Twin Sisters) }\end{array}$ & 21.2 & 3.32 & & 40 & 4.04 & $\begin{array}{l}3.98^{*} \\
3.98\end{array}$ & $\begin{array}{l}62^{*} \\
62\end{array}$ & $\begin{array}{l}3.90^{*} \\
3.25\end{array}$ \\
\hline $\begin{array}{l}\text { Dunite } \\
\text { (iron rich) }\end{array}$ & 25.1 & 3.79 & & 33 & 4.64 & $\begin{array}{l}4.60^{*} \\
4.65\end{array}$ & $\begin{array}{l}58^{*} \\
60\end{array}$ & $\begin{array}{l}3.32^{*} \\
2.60\end{array}$ \\
\hline Eclogite $†$ & 22.3 & 3.56 & & 36 & 4.14 & $3.47^{*}$ & $35^{*}$ & $3.49^{*}$ \\
\hline Fayalite & 29.11 & 4.28 & 4.39 & 26 & 5.29 & $\begin{array}{l}5.12^{*} \\
5.14\end{array}$ & $\begin{array}{l}51^{*} \\
51\end{array}$ & $\begin{array}{l}2.51^{*} \\
2.14\end{array}$ \\
\hline Forsterite & 20.10 & 3.07 & 3.21 & 40 & 3.85 & $\begin{array}{l}4.18^{*} \\
4.22\end{array}$ & $\begin{array}{l}84^{*} \\
85\end{array}$ & $\begin{array}{l}3.12^{*} \\
1.91\end{array}$ \\
\hline Granite & 20.6 & 2.63 & & 22 & 4.07 & $\begin{array}{l}3.87^{*} \\
3.93\end{array}$ & $\begin{array}{l}62^{*} \\
72\end{array}$ & $\begin{array}{l}3.75^{*} \\
1.67\end{array}$ \\
\hline Hematite & 31.94 & 5.00 & 5.27 & 31 & & $\begin{array}{l}5.80^{*} \\
5.80\end{array}$ & $\begin{array}{l}56^{*} \\
46\end{array}$ & $\begin{array}{l}2.61^{*} \\
2.27\end{array}$ \\
\hline Magnetite & 33.08 & 5.12 & 5.21 & 31 & 5.54 & $\begin{array}{l}6.01^{*} \\
6.05\end{array}$ & $\begin{array}{l}56^{*} \\
60\end{array}$ & $\begin{array}{l}2.45^{*} \\
1.95\end{array}$ \\
\hline Periclase $†$ & 20.20 & 3.59 & & 47. & & $3.63^{*}$ & $54^{*}$ & $3.95^{*}$ \\
\hline Pyrolucite & 28.98 & 4.35 & 5.23 & & & $\begin{array}{l}5.04^{*} \\
5.09\end{array}$ & $\begin{array}{l}49^{*} \\
51\end{array}$ & $\begin{array}{l}2.62^{*} \\
2.14\end{array}$ \\
\hline Quartz & 20.03 & 2.65 & 2.65 & 14 & 4.29 & $\begin{array}{l}4.04^{*} \\
4.06\end{array}$ & $\begin{array}{l}75^{*} \\
75\end{array}$ & $\begin{array}{l}2.55^{*} \\
1.06\end{array}$ \\
\hline Spinel & 20.32 & 3.42 & 3.58 & 56 & 3.86 & $\begin{array}{l}4.00^{*} \\
4.01\end{array}$ & $\begin{array}{l}71^{*} \\
72\end{array}$ & $\begin{array}{l}3.47^{*} \\
2.95\end{array}$ \\
\hline
\end{tabular}

* Raw Hugoniot data.

$\dagger$ No phase change assumed.

calculated by McQueen et al. [1967a] and the range of $\rho_{0}$ for the high-pressure phase (heavy bar below the $P=0$ line) calculated by $M c$ Queen et al. [1967a]. Materials having the same crystal structure are discussed together.

Periclase. This material has been tested by ultrasonic, X-ray, and shock-wave techniques, and apparently it remains in the starting structure to at least $2 \frac{1}{2} \mathrm{Mb}$ (Figure 2). The parameter $\left(d K_{s} / d P\right)_{0}$ for $\mathrm{MgO}$ found by ultrasonic techniques at low-pressure [Anderson and Schreiber, 1965] is 3.92 for ceramic $\mathrm{MgO}$ and 4.49 for single-crystal $\mathrm{MgO} . d K_{x} / d P$ is less than $1 \%$ higher. The X-ray results of PerezAlbuerne and Drickamer [1965] give 3.27 for this parameter from a Murnaghan fit to data to $350 \mathrm{~kb}$. The raw Hugoniot data of McQueen et al. to $1258 \mathrm{~kb}$ give 3.92 . The Hugoniot data of Al'tshuler et al. [1965] to $2600 \mathrm{~kb}$ give 3.65 . The parameter $d K / d P$ remains constant with pressure in the Murnaghan equation of state and decreases with compression in the BirchMurnaghan equation of state.

An alternative method of fitting the postphase change portion of a shock Hugoniot would be to adopt the $n$ or $\xi$ from a well de- 
TABLE 6. Birch and Birch-Murnaghan Parameters

Compiled from O. L. Anderson (personal communication), Drickamer et al. [1966], Mao [1967], and this paper.

\begin{tabular}{|c|c|c|c|c|c|c|c|}
\hline Material & $\begin{array}{c}\rho_{0} \\
\mathrm{~g} / \mathrm{cm}^{3}\end{array}$ & $\bar{M}$ & $\begin{array}{l}K_{0} \\
\mathrm{~kb}\end{array}$ & $\xi$ & $n$ & $\gamma$ & $\underset{(\mathrm{km} / \mathrm{sec})^{2}}{\Phi_{0}}$ \\
\hline \multicolumn{8}{|l|}{ Olivine } \\
\hline $\begin{array}{l}\mathrm{Mg}_{2} \mathrm{SiO}_{4} \\
\text { Spinels }\end{array}$ & 3.02 & 20.1 & 967 & -0.6 & 4.8 & 2.2 & 32 \\
\hline $\mathrm{MgO} \cdot 2.61 \mathrm{Al}_{2} \mathrm{O}_{3}$ & 3.62 & 20.1 & 2000 & -0.1 & 4.19 & 1.9 & 55 \\
\hline $\mathrm{Fe}_{1,6} \mathrm{Mg}_{0}{ }_{4} \mathrm{SiO}_{4}$ & 4.60 & 27.3 & 1980 & $0^{*}$ & $4.00^{*}$ & 1.8 & 43 \\
\hline $\mathrm{Fe}_{2} \mathrm{SiO}_{4}$ & 4.85 . & 29.1 & 2090 & $0^{*}$ & $4.00^{*}$ & 1.8 & 43 \\
\hline $\mathrm{Ni}_{2} \mathrm{SiO}_{4}$ & 5.35 & 29.9 & 2110 & $0^{*}$ & $4.00^{*}$ & 1.8 & 39 \\
\hline $\mathrm{Fe}_{2} \mathrm{FeO}_{4}$ & 5.20 & 33.1 & 1830 & $0^{*}$ & $4.00^{*}$ & 1.8 & 35 \\
\hline \multicolumn{8}{|l|}{ Post-Spinels $\dagger$} \\
\hline $\mathrm{Mg}_{2} \mathrm{SiO}_{4}$ & 4.22 & 20.1 & 87 & +1.6 & 1.9 & 0.8 & 85 \\
\hline $\mathrm{MgAl}_{2} \mathrm{O}$ & 4.01 & 20.3 & 887 & +0.8 & 3.0 & 1.3 & 72 \\
\hline Dunite & 3.98 & 21.2 & 2468 & +0.5 & 3.3 & 1.5 & 62 \\
\hline Dunite & 4.65 & 25.1 & 2790 & +1.0 & 2.6 & 1.1 & 60 \\
\hline $\mathrm{Fe}_{2} \mathrm{SiO}_{4}$ & 5.14 & 29.1 & 2621 & +1.4 & 2.1 & 0.9 & 51 \\
\hline $\mathrm{Fe}_{2} \mathrm{FeO}_{4}$ & 6.05 & 33.1 & 3630 & +1.5 & 2.0 & 0.8 & 60 \\
\hline \multicolumn{8}{|l|}{ Oxides } \\
\hline $\mathrm{MgO}$ & 3.58 & 20.2 & 1780 & 0 & 4.0 & 1.8 & 50 \\
\hline $\mathrm{FeO}$ & 5.75 & 34.5 & 1540 & +0.5 & 3.4 & 1.5 & 27 \\
\hline $\mathrm{SiO}_{2} \dagger$ & 4.28 & 20.0 & 4622 & +1.0 & 2.0 & 0.8 & 108 \\
\hline $\mathrm{Al}_{2} \mathrm{O}_{2}$ & 3.99 & 20.4 & 2713 & 0 & 4.0 & 1.8 & 68 \\
\hline
\end{tabular}

* Assumed.

$\dagger$ From metastable Hugoniot.

$\ddagger$ Stishovite $\left(4000^{\circ} \mathrm{K}\right.$ isotherm).

termined material, such as $\mathrm{MgO}$, and determine $\rho_{0}$ and $K_{0}$ from the data.

The zero-pressure bulk modulus determined from the shock-wave results is 1685 to $1950 \mathrm{~kb}$ for $\rho_{0}=3.58$ to $3.63 \mathrm{~g} / \mathrm{cm}^{3}$, which can be compared with $1717 \mathrm{~kb}$ found by ultrasonic techniques on polycrystalline $\mathrm{MgO}$.

Corundum and hematite. Both $\mathrm{Al}_{2} \mathrm{O}_{3}$ and $\mathrm{Fe}_{2} \mathrm{O}_{3}$ have been studied by static and shock compression. The Los Alamos group shocked single-crystal and ceramic corundum. There is a break in the $U_{s}-U_{p}$ curve for single-crystal corundum that could indicate the beginning of a phase change, but the break is probably due to strength effects (T. J. Ahrens and R. G. MoQueen, personal communications). The ceramic data result in a fairly well defined $\mathrm{Hu}-$ goniot (Figure 3) that extrapolates by the present technique to a density of $3.96 \mathrm{~g} / \mathrm{cm}^{3}$, which can be compared with the starting density 3.83 $\mathrm{g} / \mathrm{cm}^{3}$ and the theoretical density $3.99 \mathrm{~g} / \mathrm{cm}^{3}$. The zero-pressure bulk modulus of the highpressure data is $2693 \mathrm{~kb}$ using $\psi_{0}=0.0498$.
Low-pressure ultrasonic data give a value of $2521 \mathrm{~kb}$ for the adiabatic bulk modulus and an estimate of $2505 \mathrm{~kb}$ for the isothermal bulk modulus. Within the accuracy of the $\mathrm{X}$-ray diffraction studies of the lattice parameters of $\mathrm{Al}_{2} \mathrm{O}_{3}$ [Drickamer et al., 1966], the compressibility is independent of pressure to $300 \mathrm{~kb}$, but the rhombohedral angle increases by about $1 / 2^{\circ}$.

The hematite (Figure 4) goes through a phase change above $350 \mathrm{~kb}$, the zero-pressure density of which is about $5.80 \mathrm{~g} / \mathrm{cm}^{3}, 10 \%$ denser than the theoretical density of the lowpressure phase and about 16\% denser than the original density of the starting mineral. In the $\mathrm{X}$-ray work, the compressibility of $\mathrm{Fe}_{2} \mathrm{O}_{3}$ increases with pressure to $220 \mathrm{~kb}$, and the rhombohedral angle decreases slightly. The bulk modulus of the high-pressure phase of hematite is about $3250 \mathrm{~kb}$.

The cross on the zero-pressure abscissa of this and the following figures is the zero-pressure density that satisfies $\psi_{0}=0.0475$. 
Quartz-stishovite. The data of Wackerle [1962] for shocked quartz are shown in Figure 5. The evidence for the high-pressure phase's being stishovite is summarized by McQueen et al. [1963]. This is one of the few materials for which the zero-pressure density of the highpressure phase can be determined independently of the shock-wave data. Chao et al. [1962] determined the density of stishovite to be 4.287 $\mathrm{g} / \mathrm{cm}^{3}$. The zero-pressure density of the highpressure phase, presumably stishovite, found by the present technique is $4.06 \mathrm{~g} / \mathrm{cm}^{3}$. The scatter of the raw data is considerable, so that this is a severe test of the method.

McQueen et al. [1963] estimated $\Phi_{0}$ of stishovite to be $100(\mathrm{~km} / \mathrm{sec})^{2}$ for an assumed zeropressure density of $4.35 \mathrm{~g} / \mathrm{cm}^{3}$. The present estimate gives $\Phi_{0}=75(\mathrm{~km} / \mathrm{sec})^{2}$ for $\rho_{0}=4.06$ $\mathrm{g} / \mathrm{cm}^{3}$, and $\Phi_{0}=91(\mathrm{~km} / \mathrm{sec})^{2}$ for $\rho_{0}=4.287$ $\mathrm{g} / \mathrm{cm}^{3}$. The latter values correspond to a zeropressure bulk modulus for stishovite of $3922 \mathrm{~kb}$.

Rutile. McQueen et al. [1967b] studied single-crystal and polycrystalline $\mathrm{TiO}_{2}$ by shockwave and $\mathrm{X}$-ray techniques. At zero pressure the low-pressure phase has $\psi_{0}=+0.0440$, much lower than the other materials discussed. If this value is conserved through the phase change, the high-pressure form has a zero-pressure density of $5.71 \mathrm{~g} / \mathrm{cm}^{3}$ and a $\Phi_{0}$ of 116 $(\mathrm{km} / \mathrm{sec})^{2}$. Because of the high quality of the starting material and because of the accuracy with which $\Phi_{0}$. of the low-pressure form is known, we prefer this value to the $5.38 \mathrm{~g} / \mathrm{cm}^{3}$ value determined with $\psi_{0}=0.0475$. Assuming the slope of the phase line to be zero, $M c Q u e e n$ et al. [1967b] estimated a density of $5.8 \mathrm{~g} / \mathrm{cm}^{3}$ for the high-pressure phase.

This remarkable $34 \%$ increase in density for an already closely packed, relatively incompressible structure is interesting since the low-pressure form of rutile was the model for Thomson's early suggestion [Birch, 1952] that quartz could transform at sufficiently high pressure to a rutile-like form (stishovite). There is, however, no evidence from shock-wave data for quartz for a phase change to a material denser than stishovite [Al'tshuler et al., 1965].

Spinel and magnetite. The spinel was a ceramic material with density $3.41 \mathrm{~g} / \mathrm{cm}^{3}$, compared with the theoretical density of 3.581 $\mathrm{g} / \mathrm{cm}^{3}$. The magnetite samples were naturally occurring minerals with densities ranging from
5 to $5.14 \mathrm{~g} / \mathrm{cm}^{3}$, compared with the theoretical density of single-crystal magnetite of 5.21 $\mathrm{g} / \mathrm{cm}^{3}$. The metastable Hugoniot data indicate that spinel and magnetite undergo phase changes involving 12 and $16 \%$ increases in density, respectively, referred to zero pressure. The raw Hugoniot data give density increases of 10 and $13 \%$, respectively. The metastable Hugoniot data give densities for the high-pressure forms of spinel and magnetite that are, respectively, 2 and $7 \%$ denser than the oxides (Figures 6 and 7).

The zero-pressure densities estimated by extrapolating the metastable Hugoniot data for the high-pressure phases are 4.01 and $6.05 \mathrm{~g} / \mathrm{cm}^{3}$ for spinel and magnetite. The value of $(\rho / \bar{M})\left(\Phi_{0}^{-1 / 3}\right)$ for the low-pressure forms of both spinel and magnetite is 0.0467 . If this value is appropriate for the high-pressure phases, the inferred density will be raised by about $0.04 \mathrm{~g} / \mathrm{cm}^{3}$. These values are $13 \%$ (spinel) and $17 \%$ (magnetite) denser than the theoretical densities of the low-pressure phases that have the spinel structure and $4 \%$ (spinel) and $9 \%$ (magnetite) denser than the mixture of oxides. Fayalite and the dunites, which presumably collapse to a spinel structure at high static pressure, apparently go directly to a phase, under shock loading, that has a density very near that of the component oxides. Forsterite, however, goes to a phase about $9 \%$ denser than the oxides and about $18 \%$ denser than the spinel form.

The two light lines in Figure 6 are fits of the Murnaghan equation of state to the spinel data for two trial zero-pressure densities. They both satisfy the high-pressure data almost equally well. The range for $P_{H}$ and $P_{K}$ correspond to the range of $\rho_{0}$ indicated at $P=0$ by the heavy bar above the zero-pressure axis. For $\rho_{0}=3.90 \mathrm{~g} / \mathrm{cm}^{3}, n=4.049$, and $\Phi_{0}=55.6$ $(\mathrm{km} / \mathrm{sec})^{2}$, the relative standard deviation in density is $0.6 \%$. For $\rho_{0}=3.60 \mathrm{~g} / \mathrm{cm}^{\mathrm{s}}, n=5.26$, and $\Phi_{0}=29.3(\mathrm{~km} / \mathrm{sec})^{2}$, the relative standard deviation in density is $0.5 \%$.

Pyrolusite. This was a naturally occurring specimen and seemed to be uniform, but there is appreciable scatter in the Hugoniot data (Figure 8). The sample density was 4.35 $\mathrm{g} / \mathrm{cm}^{3}$, compared with the theoretical density of $5.23 \mathrm{~g} / \mathrm{cm}^{2}$. Assuming no phase change, a long extrapolation of the high-pressure data to 
$\psi_{0}=0.0475$ gives a zero-pressure density of $5.09 \mathrm{~g} / \mathrm{cm}^{3}$ with a large uncertainty. Pyrolusite crystallizes in the rutile structure.

Olivines. The fayalite is a naturally occurring specimen from Rockport, Massachusetts; the purity is unknown. The forsterite is a synthetic ceramic. Both undergo phase changes under shock loading. The raw Hugoniot data for the fayalite extrapolated to zero pressure give a density of $5.12 \mathrm{~g} / \mathrm{cm}^{3}$ (Figure 10). The calculated metastable Hugoniot extrapolates to $5.14 \mathrm{~g} / \mathrm{cm}^{3}$, just slightly less than the $5.29 \mathrm{~g} / \mathrm{cm}^{3}$ estimated for the density of the pure oxides $\mathrm{FeO}$ and $\mathrm{SiO}_{2}$ (stishovite). This represents a $17 \%$ increase in density over the theoretical density of fayalite in the low-pressure form.

The density of the high-pressure phase of the ceramic forsterite (Figure 9) is $4.22 \mathrm{~g} / \mathrm{cm}^{3}$, which is $0.37 \mathrm{~g} / \mathrm{cm}^{3}$ or $9.6 \%$ denser than the component oxides $\mathrm{MgO}$ plus $\mathrm{SiO}_{2}$ (stishovite). It should be pointed out that the starting forsterite material is $4.4 \%$ less dense than theoretical, whereas the starting fayalite material is $2.5 \%$ less dense. If it is assumed that the difference is due to porosity, this would result in higher temperatures and lower densities in the forsterite experiment, if the high-pressure phases have the same crystal structure.

Forsterite is anomalous when compared with results obtained with fayalite and the dunites, all of which end up near the density of the component oxides. Unfortunately, the data for forsterite are very sparse and the Hugoniot for the high-pressure phase is not well defined. In addition, there is some question about the identification of this material (R. G. McQueen, personal communication).

The spinel form of forsterite has a density of about $3.54 \mathrm{~g} / \mathrm{cm}^{3}$, so that the high-pressure form is about $19 \%$ denser than the spinel form. This can be compared with the 13 and $17 \%$ density increases of spinel and magnetite which start in the spinel structure. The spinel form of fayalite has a density of about $4.85 \mathrm{~g} / \mathrm{cm}^{3}, 5.6 \%$ less dense than the high-pressure shock phase.

Dunites. These two rocks are over 90\% olivine and transform at pressures above 0.45 $\mathrm{Mb}$. Results are comparable to the results of similar composition tested by Trunin et al. [1965]. The Twin Sisters dunite gives a zeropressure density, determined from the metastable Hugoniot of the high-pressure phase, of
$3.98 \mathrm{~g} / \mathrm{cm}^{3}$; the raw Huboniot data also yield $3.98 \mathrm{~g} / \mathrm{cm}^{3}$. The high-pressure phase is about $21 \%$ denser than the starting material and has nearly the same density as the component oxides.

The iron-rich dunite from the Transvaal contains $90 \%$ by volume of $\mathrm{Fa}_{55}$ or 34 mole \% $\mathrm{FeO}$. The density of the high-pressure phase, from the metastable Hugoniot data, is 4.65 $\mathrm{g} / \mathrm{cm}^{3}$, almost identical to the $4.64 \mathrm{~g} / \mathrm{cm}^{3}$ for the oxides. This density increase corresponds to a zero-pressure difference of $22.7 \%$. If the original material was free of pores and cracks, the starting densities would be perhaps 1 to $2 \%$ higher.

Figure 11 shows the data for the Twin Sisters dunite and the fit, for two starting densities, of the Birch-Murnaghan equation of state to the high-pressure data. A wide range of starting densities would fit the high-pressure data equally well.

The heavy horizontal bar below the $P=0$ line is the range of $\rho_{0}$ found by the analysis of McQueen et al. [1967a]; the light horizontal bars indicate the range found for the corresponding metastable Hugoniots.

Diabase. The two diabase rocks give very similar results (Figures 12 and 13). McQueen et al. [1967a] discuss the complications of interpretation and point out the anamolous compressibility of this material compared with others they tested. These rocks contain quite a bit of $\mathrm{CaO}$, which, as an oxide, is more compressible than the other common rock-forming oxides. The density of the high-pressure phase, computed as before, is about $3.7 \mathrm{~g} / \mathrm{cm}^{3}$ or about $21 \%$ denser than the starting material, and some $0.4 \mathrm{~g} / \mathrm{cm}^{3}$ less dense than the oxides. However, the presence of $\mathrm{CaO}$ also upsets the relationship between mean molar volume and elastic properties, as first pointed out by Simmons [1964]; $\mathrm{CaO}$ behaves as if it had a smaller mean atomic weight. Taking this into account would raise the estimated zero-pressure densities of the high-pressure phase by about 0.1 to $0.15 \mathrm{~g} / \mathrm{cm}^{3}$.

There is very good agreement between the metastable Hugoniots calculated here and the more elaborate calculations of McQueen et al. [1967a].

Bronzitite. McQueen et al. [1967a] shocked two bronzitites that had nearly identical compositions. We analyzed the more complete set 
of data from the Stillwater Complex, Montana (Figure 14). This rock contained 94\% enstatite, $2 \%$ oljvine, and $4 \%$ hornblende. The analysis by McQueen ct al. [1967a] yields zero-pressure values for density and $\Phi$ for the high-pressure phase that are less than the values for the lowpressure phase. We determined a density of $3.7 i$ $\mathrm{g} / \mathrm{cm}^{3}$ for the high-pressure phase, about $15 \%$ denser than the starting material, and $7 \%$ less than the oxides. Spinel plus stisluovite is abont $17 \%$ denser than the corresponding magnesiumrich enstatite.

The decomposition enstatite $\rightarrow$ forsterite + stishovite results in a density increase of about $12 \%$. The transformation enstatite $\rightarrow$ garnet would result in a density increase of about $91 / 2 \%$ [Ringuood and Major, 1960$]$ ].

Albitite and anorthosite. These rocks contain more than $90 \%$ feldspar, and both undergo phase changes at relatively low pressures which involve large volume changes. The computed zero-pressure density of the high-pressure phast albitite (Figure 15), which is $98 \%$ by volumo $\mathrm{an}_{1: 2}$ and $2 \%$ actinolite, is $3.75 \mathrm{~g} / \mathrm{cm}^{3}$, a $43.7 \%$ increase over the starting density. This is about $0.1 \mathrm{~g} / \mathrm{cm}^{3}$ less dense than the equivalent pure oxides and about $0.25 \mathrm{~g} / \mathrm{cm}^{3}$ denser than jadeite plus stishovite. Jadeite itself undergoes a phase change above $0.55 \mathrm{Mb}$.McQuecen ct al., 1967a], but the density increase cannot be established with present data.

The zero-pressure density of the anorthosite (Figure 15), which is $90 \%$ by volume feldspar $\left(a n_{40}\right)$ and $10 \%$ pyroxene (aid), is $3.65 \mathrm{~g} / \mathrm{cm}^{3}$. This represents at density increase of about $32.7 \%$ over the starting material and is 0.26 $\mathrm{g} / \mathrm{cm}^{*}$ less dense than the oxides.

(iranite. The granite sample (Figure 17) was from Westerly, Rhode Island, and contained about $28 \%$ quartz, $35 \%$ microrline, and $31 \%$ plagioclase, The inferred zern-pressure density of the high-pressure phase is $3.99 \mathrm{~g} / \mathrm{cm}^{3}$ or about $49 \%$ denser than the starting material. This can be compared with the $62 \%$ density increase for the quartz 10 stishovito transformation, $44 \%$ for alhitite, and $33 \%$ for anorthosite, the latter two being feldspar-rich rocks. Apparently both the quartz and the feldspars in the granite have transformed to more dense phases. The high-pressure phase assemblate in granits is $3 \%$ less dence than the pure oxides.

Erlogite. We interpreted only the Summore,
Norway, eclogite (Figure 18) initial density about $3.56 \mathrm{~g} / \mathrm{cm}^{3}$. McQueen et al. believe that a phase change is indicated at about $0.37 \mathrm{Mb}$ but that the high-pressire data mity be still in the mixed phase region or that the phase change is second order rather than first order. The highpressure datia are clearly anomalous in that the inferred zero-pressure density and $\Phi_{0}$ are both less than for the low-pressure phase. Consequently, the high-pressure data are probably in the mixed phase region and the estimater zero-pressure parameters are not useful for present purposes.

Achnowledgments. We are very griteful to R. G. MrQueen, S. P. Marsh, and J. N. Fritz for kindly allowing us to see their datia in advanee of publintion. These data were initially brought to our attention by Francis Birch. Martin Smith issisted in the analysis.

This researeh was partially supported by the Air Force Oflice of Scientific Research, Office of Arrospace Resentreh, Itnited States Air Force, undor AFOAR contrit AF-49(638)-1337.

\section{RAFERNCES}

Alurens, T. J., D. L. Anderson, and A. E. Ringwood. Shock waye equations of state (in preparation), 1968.

Altshuler, L. V., R. F. Trunin, and G. V. Simakov, Shock-wave compression of periclise and quartz and the composition of the earth's lower mantle, Izv. Phys. Solin Earth. English 'Transl., no. 10, $657-660,1965$.

Anderson, Don L., A seismic equation of state, Geophys. J., 13,9-30, 1967.

Audersou, J)on L., and T. J. Ahrens. Equation of stite of high-pressure phases from shock wave data (abstract), Thoms. Am. Geophys. Union, h? $309,1968$.

Anderson, O. T., and E. Sohreiber, The pressure derivative of the sound velocites of polyerrstalline magnesia. J. Gconllys. Res.. $\%$ (1.5241-5248, 1965.

Bireh, F., Flasticity and constitution of the earth's interior, t. Geoph hs. Res. 57. 227 286, 1952.

Chao. J. C. T., J. J. Falney, J. Litter, and D. J. Milton. Stishorite. SiO, a very high pressure new mueral from Meteor Crater, Arizona, $J$. Gcolltes. Res., oi, 419-421, 1962.

Clark. S. P.. Jr., Equation of state and polymorphisn at high pressures, in Research in Geochrmialry, edited by P. H. Abelson, Jobn Wiley. New York, 1959.

Clark, S. P.. Jr.. (Ed.). Handbook of Physical Comstants, Memoir 97. Geolngient Society of Anerica, Now York, 1966.

Drickamer, H. G.. R. W. Ityorh, R. I. Clendenen, and F. A. Perez-dthuerne. X-ray diffraction studies of the lattioe parameters of solids under 
very high pressure, Solid State Phys., 19, 135$228,1966$.

Mao, Ho-kwang, The pressure dependence of the lattice parameters and volume of ferromagnesian spinels, and its implications to the earth's mantle, Ph.D. thesis, University of Rochester, Rochester, N. Y., 1967.

McQueen, R. G., J. N. Fritz, and S. P. Marsh, On the equation of state of stishovite, J. Geophys. Res., 68, 2319-2322, 1963.

McQueen, R. G., S. P. Marsh, and J. N. Fritz, Hugoniot equation of state of twelve rocks, J. Geophys. Res., 7. 4999-5036, 1967a.

McQueen, R. G., J. C. Jamieson, and S. P. Marsh, Shock-wave compression and X-ray studies of titanium dioxide, Science, 155, 1401-1404, $1967 b$.

Perez-Albuerne, E. A., and H. G. Drickamer, The effect of high pressure on the compressibilities of seven crystals having the $\mathrm{NaCl}$ structure, $J$. Chem. Phys., 43, 1381-1385, 1965.

Ringwood, A. E., Mineralogy of the mantle, in
Advances in Earth Science, edited by P. M. Hurley, M.I.T. Press, Cambridge, Mass., 1966.

Ringwood, A. E., and A. Major, High-pressure transformations in pyroxenes. Earth Planetary Sci. Letters, 1, 351-357, 1966.

Simmons, G., Velocity of shear waves in rocks to 10 kilobars, 1, J. Geophys. Res., 69, 1123-1130, 1964.

Takeuchi, H., and H. Kanamori, Equations of state of matter from shockwave experiments, J. Geophys. Res., 71, 3985-3994, 1966.

Trunin, R. F., V. I. Gonshakova, G. V. Simakov, and N. E. Galdin, A study of rocks under the high pressures and temperatures created by shock compression, Izv. Phys. Solid Earth, no. 9, 579-586, 1965.

Wackerle, J., Shock-wave compression of quartz, J. Appl. Phys., 33, 922-937, 1962.

(Received March 2, 1968.) 